\title{
LA ANTROPONIMIA DE EJEA DE LOS CABALLEROS EN EL SIGLO XIII: UN ANÁLISIS DE LA DOCUMENTACIÓN PARROQUIAL (1241-1299)
}

\author{
THE ANTHROPONYMY OF EJEA DE LOS CABALLEROS IN THE 13 ${ }^{\text {th }}$ CENTURY (1241-1299): \\ AN ANALYSIS OF PAROCHIAL DOCUMENTATION
}

Resumen: El trabajo analiza la antroponimia de los veinte documentos comprendidos entre 1241 y 1299 que se conservan en el Archivo Parroquial de Ejea de los Caballeros (Cinco Villas, Zaragoza). Ciento treinta años después del inicio de la repoblación de la villa, el estudio confirma la estabilización del sistema antroponímico de doble nombre, con predominio de los nomina paterna y un porcentaje significativo de antropónimos que contienen una indicación geográfica. El estudio también arroja luz sobre los conflictos sobrevenidos en el seno de la iglesia de Ejea en el siglo XIII y sobre el proceso de su formación patrimonial.

Palabras clave: antroponimia medieval aragonesa, antroponimia eclesiástica, siglo XIII, Ejea de los Caballeros, Reino de Aragón.

\author{
Marcelino CORTÉS VALENCIANO \\ IES «Las Llamas», Santander \\ marcelinocortes@gmail.com
}

\begin{abstract}
The work analyses the anthroponimy of the twenty documents from 1241 to 1299 held in the Parochial Archives of Ejea de los Caballeros (Zaragoza). One hundred and thirty years after the beginning of the repopulation of the village, the study confirms the stabilization of the anthroponimic double name system, with a predominance of the nomina paterna and a significant percentage of anthroponims which contain a geographical indication. The study also sheds light on the conflicts which have taken place within the church in Ejea in the $13^{\text {th }}$ Century and on the process of its heritage formation.
\end{abstract}

Key words: Aragonese medieval anthroponimy, ecclesiastical anthroponimy, $13^{\text {th }}$ century, Ejea de los Caballeros, Kingdom of Aragon. 


\section{Introducción}

Este trabajo pretende averiguar cuál era el sistema antroponímico de la villa zaragozana de Ejea de los Caballeros ciento treinta años después de que el rey Alfonso I le otorgara fueros, «concediendo ingenuidad y franqueza ciudadana semejante a la infanzonía a todos los pobladores presentes y futuros, así como a sus propiedades» (Falcón, 2007: 298). Y lo vamos a realizar a través de los documentos del Archivo Parroquial de Ejea de los Caballeros (APE), único fondo documental que permite la aproximación más completa y sistemática a la cuestión. ${ }^{1}$

Desde hace ya algunas décadas se ha venido subrayando la importancia que posee la antroponimia como una herramienta a través de la cual se pueden analizar distintos procesos como las migraciones, la configuración de áreas culturales o los grupos sociales que se desarrollan en la Edad Media (Martínez Sopena, 1995: 11-12). Esta labor, que ha sido posible gracias al estudio de las compilaciones documentales correspondientes a distintos reinados, tramos cronológicos o grandes movimientos de población, como los que se sucedieron en el Valle del Ebro entre los siglos XI-XII, debe ser complementada con el análisis particular de comunidades que se formaron como consecuencia de fenómenos de repoblación, como es el caso que nos ocupa. ${ }^{2}$

Para lograr ese objetivo se describen, en primer lugar, los fondos documentales de donde hemos obtenido el corpus antroponímico y se justifica la toma de decisiones. En segundo lugar, se clasifican los antropónimos en función de su estructura. De este análisis se deducirán unos datos estadísticos que permitirán compararlos con los obtenidos en otros lugares, averiguar cuál es el sistema antroponímico de Ejea de los Caballeros en el siglo XIII y, de paso, obtener información sobre los conflictos que se produjeron en el capítulo de la iglesia de Ejea en esa época y conocer el proceso de formación de su patrimonio.

1 «Es evidente que los materiales antroponímicos admiten una gran diversidad de enfoques; creemos, sin embargo, que es en el análisis de corpus documentales donde más sugestivo y fecundo aparece el estudio antroponímico» (Frago, 1976: 73).

2 Como señala Guinot (2010: 195), «las variaciones en la forma de denominarse la gente a lo largo de los siglos medievales [...] puede y debe ser cuantificado, ordenado en tantos por ciento indicativos para los diversos países o regiones y los diversos periodos cronológicos». El estudio antroponímico de las Cinco Villas es una tarea pendiente de realizar (Gil y Auría, 2007: 323-436). 


\subsection{El Archivo Parroquial de Ejea de los Caballeros}

El Archivo Parroquial de Ejea de los Caballeros se custodia en el despacho parroquial de la villa. ${ }^{3}$ Allí se guardan los fondos documentales de las dos parroquias tradicionales de Ejea, la de Santa María, consagrada en 1174, y la de San Salvador, que lo fue en 1222. Es probable que cada una de estas parroquias contara con su propio archivo durante la Edad Media y que el actual sea el resultado de la reunificación de ambos depósitos documentales, pero esta hipótesis no ha podido ser confirmada por ninguna vía (Auría, 1982: 3; Cortés, 2015-2016: 15).

La catalogación en el APE de los documentos anteriores al siglo XV no sigue un orden cronológico y los pergaminos están sin numerar. En su lugar, los fondos medievales se agrupan en doce bloques temáticos: letras de posesión, testamentos, aniversarios, arrendamientos, donativos, ventas, requerimientos, liquidaciones, procuras, pleitos, capellanías y varios.

Los fondos documentales del APE fueron objeto de un trabajo monográfico por parte de José Ramón Auría Labayen (1982) titulado Documentación medieval del Archivo Parroquial de Ejea de los Caballeros: transcripción (DAPE). ${ }^{4}$ Entre otros muchos méritos, este estudio establece un orden cronológico de todos los documentos del archivo parroquial comprendidos entre 1174 y 1499 , por lo que se convierte en un referente inexcusable a la hora de consultar los fondos y establecer las referencias necesarias.

El documento más antiguo que se guarda en el APE es el acta de consagración de la iglesia de Santa María, que está datada en el mes de abril de $1174 .{ }^{5}$ Desde esa fecha hasta mayo de 1241 no se conserva ningún otro documento en el archivo. Entre estos dos pergaminos se extiende, pues, un vacío documental de sesenta y siete años.

Desde 1241 hasta 1299 se guardan veinte pergaminos, que son los que hemos seleccionado para la elaboración de este trabajo. De nuestro análisis hemos exceptuado el acta de consagración de la iglesia de Santa María por dos razones: en primer lugar, por la especificidad del acto del que se deja constan-

3 Desde estas líneas quiero agradecer al párroco Pedro Segura las facilidades para la consulta del archivo y la ayuda de José Manuel Monguilod para la localización de los documentos.

4 Se trata de su tesis de licenciatura (septiembre de 1982) y fue dirigida por Agustín Ubieto Arteta. Este estudio está sin publicar. Se ha consultado el ejemplar mecanografiado que forma parte de los fondos del Centro de Estudios de las Cinco Villas de la Institución Fernando el Católico.

5 El acta ha sido objeto de un estudio específico por Monterde (2006: 391-396). 
cia; y en segundo lugar, para preservar la unidad del análisis en torno a un tracto cronológico concentrado básicamente en la segunda mitad del siglo XIII. En todo caso, nuestro trabajo informa sobre el estadio antroponímico más antiguo de Ejea de los Caballeros que, a falta de censos, es posible reconstruir a partir de la documentación de que disponemos.

Por una cuestión procedimental mantenemos el orden de la numeración de los documentos que estableció Auría (1982) en su trabajo para referirnos a los que analizamos. Y puesto que hemos exceptuado del estudio el acta de consagración de la iglesia de Santa María que en el DAPE se numera en primer lugar, las referencias documentales utilizadas en este estudio comprenden del documento 2 al documento 21. De estos veinte pergaminos, diez están escritos en latín ${ }^{6}$ y los otros diez en romance. ${ }^{7}$

La cronología de los documentos del siglo XIII analizados es la siguiente: ${ }^{8}$

Tabla 1. Numeración y cronología de los documentos analizados.

\begin{tabular}{|l|l|}
\hline Numeración DAPE & Fecha \\
\hline Doc. 2 & 31 de mayo de 1241 \\
\hline Doc. 3 & Agosto de 1243 \\
\hline Doc. 4 & 25 de agosto de 1254 \\
\hline Doc. 5 & Mayo de 1256 \\
\hline Doc. 6 & 1 de junio de 1263 \\
\hline Doc. 7 & 1 de julio de 1263 \\
\hline Doc. 8 & 21 de marzo de 1273 \\
\hline Doc. 9 & 16 de mayo de 1274 \\
\hline Doc. 10 & 3 de noviembre de 1274 \\
\hline Doc. 11 & 12 de septiembre de 1277 \\
\hline Doc. 12 & 10 de febrero de 1279 \\
\hline Doc. 13 & 21 de marzo de 1279 \\
\hline
\end{tabular}

6 Según la numeración de DAPE, se corresponden con los documentos 2, 3, 4, 5, 6, 7, 8, 11, 14 y 17.

7 Según la numeración de DAPE, se corresponden con los documentos 9, 10, 12, 13, 15, 16, 18, 19, 20 y 21. Los seis primeros documentos en romance - fechados entre 1274 y 1286 - han sido editados y analizados desde el punto de vista lingüístico en Cortés (2015-2016: 13-71).

8 A pesar de la cronología aproximada del documento 18, mantenemos el orden asignado en DAPE para este documento. 


\begin{tabular}{|l|l|}
\hline Doc. 14 & 24 de abril de 1283 \\
\hline Doc. 15 & 29 de septiembre de 1284 \\
\hline Doc. 16 & 22 de diciembre de 1286 \\
\hline Doc. 17 & 29 de septiembre de 1287 \\
\hline Doc. 18 & ca. $1300 ~ ¿ ?$ \\
\hline Doc. 19 & 10 de julio de 1295 \\
\hline Doc. 20 & 10 de octubre de 1297 \\
\hline Doc. 21 & 28 de noviembre de 1299 \\
\hline
\end{tabular}

\subsection{Contenido de los documentos estudiados}

El contenido de estos documentos es heterogéneo, aunque pueden establecerse dos grupos. En el primero se incluyen aquellos actos jurídicos que habitualmente se encuentran en este tipo de archivos. Este grupo contiene cuatro aniversarios (docs. 6, 7, 12 y 13), tres ventas entre particulares y el capítulo de los clérigos de Ejea (docs. 2, 4 y 15), ${ }^{9}$ tres donaciones (docs. 5,19 y 21), ${ }^{10}$ dos pleitos (docs. 16 y 18), ${ }^{11}$ un treudo de una viña y un campo (doc. 3$),{ }^{12}$ un testamento (doc. 20) ${ }^{13}$ y la copia de una orden de Alfonso III de Aragón prohibiendo que se cursen las cartas de Fortunio de Vergua (qui se falso modo gerit) y que no se obedezca al Obispo de Zaragoza (doc. 17). ${ }^{14}$

El segundo grupo de documentos presenta un carácter unitario al formar parte de un mismo proceso. Se trata del pleito que mantienen los clérigos racioneros y no racioneros de Ejea sobre el reparto de aniversarios, pechas y otro tipo de prerrogativas eclesiásticas. Por lo que se deduce de estos docu-

9 Estas ventas son las siguientes: una pieza en Luchán (doc. 2), una viña en Camarales (doc. 4) y unas casas situadas junto al cementerio de la iglesia de San Salvador (doc. 15).

10 Se donan una viña en Facemón (doc. 5), unas casas en la parroquia de San Salvador (doc. 19) y tres viñas en Camarales (doc. 21)

11 El primero es una sentencia dictada por el baile de la Corte de Ejea contra Maria Sanchez por el incumplimiento del treudo de una viña en Camarales que era propiedad del capítulo (doc. 16). El segundo es un pleito entre los clérigos racioneros de Ejea y los de Biota por un aniversario (doc. 18).

12 El capítulo de clérigos racioneros da a Domingo Ezquerrer una viña en Camarales y un campo en Madriguera por dos sueldos dineros jaqueses anuales.

13 Dictan el testamento Sancho Lopeç de Vrez y su esposa Maria Lopeç, vecinos de Ejea. Eligen sepultura y dividen sus bienes, dejando a Pero Capalbo y a Dominsanç del Forno como albaceas.

14 Hoc est traslatum bene et fideliter extractus quodam littera domini regis in dorso sigilata. La orden se dirige a las iglesias de Ejea, Luna, Tauste, Alagón, Castellar, Zuera ac aliorum locorum nostrorum diocesis cesaraugustane (DAPE, doc. 17). 
mentos, este conflicto venía de lejos y los documentos conservados nos lo muestran in medias res. En el documento 8 (marzo de 1273) se recoge la apelación del procurador de los clérigos racioneros de Ejea, Fortuño de Alvero, a la diócesis de Pamplona en la que muestra su disconformidad con una sentencia anterior dictada por Pedro de Falabo, arcediano del Valle de Aibar. Los documentos 9 y 10 poseen el mismo tenor diplomático, están escritos en fechas muy próximas (mayo y noviembre de 1274 respectivamente) y contienen sendos nombramientos - de procuradores el primero, de árbitros el segundo - para resolver la disputa planteada. El documento 11 es una copia del documento que asigna la cuantía de las raciones de los clérigos racioneros y está dado por el procurador de las diócesis de Zaragoza y Pamplona tres años más tarde (septiembre de 1277). El documento 14, dado en Zaragoza el 24 de abril de 1283, es una secuela de todo este conflicto y contiene una declaración en la que se reitera que los clérigos racioneros no son servidos de dar distribuciones a los clérigos no racioneros. ${ }^{15}$

\subsection{Elaboración del corpus}

Para la preparación del trabajo hemos realizado el cotejo de la transcripción realizada por Auría (1982) con la revisión de los pergaminos originales. Salvo casos puntuales, ${ }^{16}$ ratificamos la lectura de los antropónimos realizada por este autor. A continuación, hemos procedido al vaciado de los antropónimos en fichas en donde se anota el registro documental, la forma antroponímica y la contextualización social de la persona. ${ }^{17}$ El resultado de este vaciado reporta un total de doscientos seis antropónimos. La relación completa de todos ellos se recoge en el anexo I de este trabajo, juntamente con el número del documento en que aparecen.

Puesto que el análisis está focalizado en el estudio de las personas constitutivas de una comunidad concreta - Ejea de los Caballeros - en un periodo

15 En el año 1340 se realizó el reparto de los lotes o suertes entre los componentes del capítulo de los clérigos racioneros. Esta fecha es clave para el estudio de la formación del patrimonio territorial de la iglesia de Ejea y es la utilizada por Auría (1982: 4-17) en su estudio introductorio para dividir en dos etapas este proceso.

16 Las lecturas divergentes son las que siguen: Gorreia en lugar de Gorriza (doc. 2); Gil de Lopinnen en lugar de Gil de Lopeine (doc. 9); Martin Suari en lugar de Martin Suau (doc. 10); Petrus Suario en lugar de Petrus Suarzo (doc. 11); Bartholomeu del Farno en lugar de Bartholomeu del Furnu (doc. 11); Garcias Larcas en lugar de Garcias Lactas (doc. 11); Rodrigo de Aldaz en lugar de Rodrigo de Aidaz (doc. 13).

17 Esta ficha sigue el modelo al uso recogido por Martínez (coord.) (1995: 19). 
de tiempo concreto — de 1241 a 1299-, hemos exceptuado del estudio los nombres de aquellas personas, autoridades y clérigos ajenos a esta comunidad. La mayor parte de ellos participan en el pleito ya citado entre clérigos racioneros y no racioneros, y se recogen en el anexo I separados del resto. Estos nombres - veintidós en total — no entran a formar parte de ningún cómputo ni estadística de las que seguidamente se incluyen, por lo que el corpus neto que va a ser objeto de estudio en este artículo asciende a ciento ochenta y cuatro antropónimos.

En la Tabla 2 puede observarse la distribución - hombres, mujeres y clérigos- del corpus de los 184 antropónimos analizados:

Tabla 2. Distribución del corpus analizado.

\begin{tabular}{|l|l|l|}
\hline & Número & Porcentaje \\
\hline Hombres & 111 & $60.3 \%$ \\
\hline Mujeres & 13 & $7.1 \%$ \\
\hline Clérigos & 60 & $32.6 \%$ \\
\hline TOTAL & 184 & $100 \%$ \\
\hline
\end{tabular}

Con respecto al registro de la forma antroponímica, cabe establecer varias precisiones. En primer lugar, y siempre que una persona es designada de dos maneras, se ofrece la forma más compleja. Por ejemplo, en el documento 2 se menciona a Sanio de Peruxa, que reaparece en el documento 11 con su forma completa Petrus Sancii de Peruxa; el documento 6 lo encabeza el clérigo racionero de Ejea Petrus Luppi, que vuelve a aparecer en el documento 12 como Pero Lopeç d'Uchando.

En segundo lugar, cuando un nombre alterna la forma latina con la forma romance, se indexa bajo la segunda, dejando constancia entre paréntesis de esa duplicidad junto al número del documento en donde aparece. Por ejemplo, Johannes Petri de Falçes (doc. 8) tiene entrada en el anexo I como Johan Pereç de Falçes (docs. 9 y 10); en septiembre de 1277 aparece como clérigo racionero Sancius de Rippis (doc. 11), al que en julio de 1295 se menciona, ya finado, como Sanyo de Ribas (doc. 19). En aquellos casos en que consta de forma explícita, se añade también la indicación social (dominus, dona, milites, scutiferus, etc.).

Por último, dejamos constancia de que, en algunos casos, el estado de los pergaminos y la ilegibilidad de algunos fragmentos no nos han permitido la 
reconstrucción completa de los nombres. Esta circunstancia afecta especialmente a los documentos 2, 5, 10, 14 y 18. En el anexo I, y separados del resto, se deja constancia de aquellos antropónimos cuya lectura ha sido fragmentaria. Estos nombres de lectura incompleta —ocho en total — tampoco forman parte de los cómputos y estadísticas que se encontrarán en las páginas siguientes.

\section{Análisis de los datos}

\subsection{Las formas antroponímicas}

El análisis de los ciento ochenta y cuatro antropónimos procedentes de la documentación del siglo XIII del Archivo Parroquial de Ejea depara la siguiente clasificación según la forma antroponímica utilizada (Tabla 3):

Tabla 3. Clasificación de las formas antroponímicas. Datos directos.

\begin{tabular}{|c|c|c|c|}
\hline \multirow{2}{*}{ Estructuras } & \multicolumn{2}{|c|}{ Laicos } & \multirow{2}{*}{ Clérigos } \\
\hline & Hombres & Mujeres & \\
\hline 1. Nombre único & 3 & 1 & 1 \\
\hline \multicolumn{4}{|c|}{ 2. Nombre + designación complementaria } \\
\hline 2.2. Hijo de & 1 & 1 & \\
\hline 2.2. Otra relación familiar & & 2 & \\
\hline $\begin{array}{l}\text { 2.3. Nombre }+ \text { designación de } \\
\text { tipo profesional }\end{array}$ & 1 & & 2 \\
\hline \multicolumn{4}{|c|}{ 3. Formas antroponímicas de dos elementos } \\
\hline 3.1. Nombre + patronímico & 46 & 6 & 24 \\
\hline 3.2. Nombre + toponímico & 34 & 3 & 12 \\
\hline 3.3. Nombre + otras indicaciones & 4 & & 4 \\
\hline \multicolumn{4}{|l|}{ 4. Formas complejas } \\
\hline $\begin{array}{l}\text { 4.1. Nombre + patronímico + } \\
\text { indicación de lugar }\end{array}$ & 13 & & 10 \\
\hline $\begin{array}{l}\text { 4.2. Nombre }+ \text { patronímico }+ \\
\text { indicación familiar }\end{array}$ & 9 & & 7 \\
\hline \multirow{3}{*}{ TOTALES } & 111 & 13 & \\
\hline & \multicolumn{2}{|c|}{124} & 60 \\
\hline & \multicolumn{3}{|c|}{184} \\
\hline
\end{tabular}


Si agrupamos estos datos directos y los trasvasamos a términos porcentuales, el resultado queda reflejado en la Tabla 4:

Tabla 4. Clasificación de las formas antroponímicas.

Datos directos agrupados y porcentuales.

\begin{tabular}{|c|c|c|}
\hline Estructuras & Número & $\%$ \\
\hline 1. Nombre único & 5 & $2.7 \%$ \\
\hline \multicolumn{3}{|l|}{ 2. Nombre + designación complementaria } \\
\hline 2.1. Hijo de & 2 & $1.1 \%$ \\
\hline 2.2. Otra relación familiar & 2 & $1.1 \%$ \\
\hline 2.3. Nombre + designación de tipo profesional & 3 & $1.6 \%$ \\
\hline \multicolumn{3}{|l|}{ 3. Formas antroponímicas de dos elementos } \\
\hline 3.1. Nombre + patronímico & 76 & $41.4 \%$ \\
\hline 3.2. Nombre + toponímico & 49 & $26.6 \%$ \\
\hline 3.3. Nombre + otras indicaciones & 8 & $4.3 \%$ \\
\hline \multicolumn{3}{|l|}{ 4. Formas complejas } \\
\hline 4.1. Nombre + patronímico + indicación de lugar & 23 & $12.5 \%$ \\
\hline 4.2. Nombre + patronímico + indicación familiar & 16 & $8.7 \%$ \\
\hline TOTAL & 184 & $100 \%$ \\
\hline
\end{tabular}

Sumados los porcentajes de los distintos subapartados, la representación gráfica de la tabla anterior es la siguiente:

Gráfico 1. Distribución porcentual de la clasificación de las formas antroponímicas.

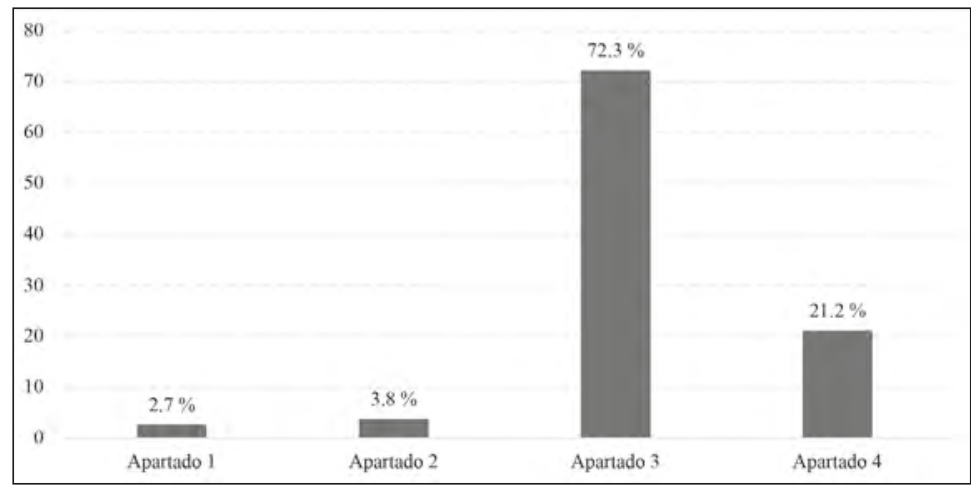


La primera conclusión que se extrae del análisis de estos datos es evidente: nos encontramos ante un sistema antroponímico compuesto mayoritariamente por dos elementos (nombre + apellido) que representa el $72.3 \%$ del corpus analizado (apartado 3). A su vez, y dentro de este apartado, es hegemónica la forma compuesta por nombre + patronímico (apartado 3.1), con setenta y seis antropónimos, lo que representa el $41.4 \%$ del corpus. Estos datos corroboran la conclusión general de que «el siglo XIII marca, al menos en la Corona de Aragón, el periodo de maduración del doble nombre y la consolidación de la transmisión de padres a hijos del apellido» (Guinot, 2010: 200). Y destaca, en segundo lugar, el número de antropónimos que reportan una indicación de lugar (apartado $3.2+$ apartado 4.1). Son, en total, setenta y dos antropónimos (39.1\%).

En estos resultados se constata también cómo el nomen singulare (apartado 1), que tanta pujanza tuvo en los siglos anteriores en los reinos de Navarra y Aragón, ${ }^{18}$ es completamente residual $(2.7 \%)$. También es muy escasa la presencia del nombre único acompañado por una designación complementaria (3.8 \%), ya sea de carácter familiar o profesional (apartado 2). Estas conclusiones generales son compartidas tanto por la antroponimia masculina laica como por la clerical. La única diferencia significativa entre ambos grupos antroponímicos se observa en el porcentaje de la forma nombre + toponímico (apartado 3.2), con mayor frecuencia en los laicos que en los clérigos. ${ }^{19}$

En lo que respecta a la antroponimia femenina, las conclusiones son necesariamente más limitadas por la contracción numérica de la muestra obtenida. Como ya hemos señalado, en el corpus documental estudiado se identifican trece mujeres, lo que se traduce en términos porcentuales en un $7.1 \%{ }^{20} \mathrm{La}$ antroponimia femenina del APE también se caracteriza por la prevalencia de las formas antroponímicas compuestas por dos nombres. Nueve de los trece nombres femeninos $(69.2 \%)$ se ajustan a esta estructura, lo que representa un porcentaje similar al de la antroponimia masculina. ${ }^{21}$ Los cuatro nombres res-

18 Para Navarra, vid. García de Cortázar (1991: 175-191 y 1995: 283-296) y Cierbide (2017: 10-21). Para el Reino de Aragón, vid. Laliena (1995: 297-326) y Fort (1992: 969-980).

19 En los hombres laicos, treinta y cuatro sobre ciento once (30.6\%); en los clérigos, doce sobre un total de sesenta $(20 \%)$.

20 A modo de referencia, en la documentación procedente de Leire el porcentaje de mujeres asciende al $12.9 \%$ entre 1051-1100 y desciende al 8.1 \% entre 1101-1130 (García de Cortázar, 1995: 294). En la documentación aragonesa manejada por Laliena (1995: 322) entre 1062-1110 el porcentaje de nombres femeninos se sitúa en el 12.7 \%; en el siglo XII — a partir del cartulario de La Seo- este porcentaje se eleva al $23.4 \%$.

21 Seis de estos nueve nombres contienen la estructura nombre + patronímico (apartado 3.1) y tres de ellos responden al modelo nombre + toponímico (apartado 3.2). 
tantes $(30.8 \%)$ están formados por el nombre de bautismo y una designación complementaria de carácter familiar (hija de ..., viuda de..., mujer de...). ${ }^{22}$

\subsection{Los nombres de bautismo}

El estudio de los nombres de bautismo de la antroponimia masculina laica refleja la utilización de treinta y tres nombres diferentes para designar a ciento once hombres. Estos nombres de bautismo, ordenados de mayor a menor frecuencia en la Tabla 5, son los siguientes:

Tabla 5. Frecuencia de los nombres de bautismo masculinos.

\begin{tabular}{|c|c|c|}
\hline SANCTIUS & San, Sancho, Sanchius, Sancius, Sanio, Sanyo & 15 \\
\hline PETRUS & Pero, Petrus, Petro & 13 \\
\hline GARCIA & Garcia, Garçia, Garsias & 13 \\
\hline DOMINICUS & Domingo, Dominice, Dominico, Dominicus & 12 \\
\hline IOHANNES & Johan, Ioannis, Iuannes, Johannes & 10 \\
\hline XIMENUS & Exemen, Exemeno, Eximeno, Eximenus, Xemen & 6 \\
\hline MICHAELIS & Michael, Michaelis, Miguel & 4 \\
\hline ENNECUS & Enego, Eniego, Enneco & 3 \\
\hline FORTUNIUS & Fortunius, Fortunno, Frotum & 3 \\
\hline GUILLERMUS & Gil, Guillem & 3 \\
\hline MARTINUS & Martin, Martino, Martinus & 3 \\
\hline ACENARIUS & Açnarius, Aznar & 2 \\
\hline BARTHOLOMEUS & Bartholomeo, Bartholomeu, Bartholomeus & 2 \\
\hline BERTRANDUS & Beltran, Bertrando & 2 \\
\hline ARNALDUS & Arnaldi, Arnalt & 2 \\
\hline $\begin{array}{l}\text { RESTO DE NOMBRES } \\
\text { (UN SOLO CASO POR } \\
\text { NOMBRE) }\end{array}$ & $\begin{array}{l}\text { Acach, Bernardi, Boneti, Corbaran, Diego, Egidius, } \\
\text { Estevan, Ferrando, Ferrer, Gatan, Jurdan, Lop, } \\
\text { Matheu, Nicholaus, Paschual, Pelegrin, Philippus, } \\
\text { Remigiro }\end{array}$ & 18 \\
\hline \multicolumn{2}{|l|}{ TOTAL } & 111 \\
\hline
\end{tabular}

22 Como recuerda Laliena (1995: 322), «las mujeres suelen aparecer en los documentos de manera subordinada - compartiendo las decisiones sobre tierras o bienes de los maridos, hermanos o padres-, lo que tiene serias repercusiones en un sistema de identificación que se apoya decididamente en los hombres de su entorno». 
Esta diversidad de nombres es, sin embargo, aparente, puesto que los seis primeros comprenden el $62.1 \%$ de los hombres. De esta manera, se deduce que los nombres de bautismo más frecuentes son, por este orden, Sancho, Pedro, García, Domingo, Juan y Jimeno. Estos datos prolongan la tendencia onomástica del siglo XII en el Valle del Ebro, en donde los nombres individuales más utilizados fueron Pedro, Juan, Sancho, García y Domingo. ${ }^{23}$

En el caso de la antroponimia de los clérigos, los resultados quedan expresados en la Tabla 6:

Tabla 6. Frecuencia de los nombres de bautismo de los clérigos.

\begin{tabular}{|l|l|c|}
\hline IOHANNES & Johan, Ioannis, Iuannes, Johannes & 10 \\
\hline PETRUS & Pero, Petro & 9 \\
\hline XIMENUS & Exemen, Exemeno, Eximenus, Xemen & 7 \\
\hline GARCIA & Garcia, Garçia, Garsias & 6 \\
\hline SANCTIUS & Sancho, Sanyo & 3 \\
\hline MICHAELIS & Michael, Miguel & 3 \\
\hline GUILLERMUS & Guillem, Guillermus & 2 \\
\hline MARTINUS & Martin & 2 \\
\hline ACENARIUS & Açnar, Aznar & 2 \\
\hline BARTHOLOMEUS & Bartholomeu & 2 \\
\hline BERTRANDUS & Beltran & 2 \\
\hline FERRANDUS & Fernando, Ferran & 8 \\
\hline RODERICUS & Rodrigo & 60 \\
\hline $\begin{array}{l}\text { RESTO DE NOMBRES } \\
\text { (UN SOLO CASO POR } \\
\text { NOMBRE) }\end{array}$ & \begin{tabular}{l} 
Adam, Alvaro, Blascho, Egidio, Estevan, Fortu- \\
\hline TOTAL
\end{tabular} & 2 \\
\hline
\end{tabular}

23 Laliena (1995: 317-318). Estos cinco nombres reúnen entre el $42.3 \%$ y el $50.5 \%$ de las designaciones personales en la antroponimia del Valle del Ebro en el periodo comprendido entre 1125 y 1200 . En Navarra los siete nombres masculinos dominantes entre los años 920-1160 son García, Sancho, Eneco, Fortún, Lope, Jimeno y Aznar. Estos «siete nombres masculinos dominantes son llevados por más de un 70 por ciento de la población» (García de Cortázar, 1995: 292). Los datos son muy similares en la documentación navarra de 1283 estudiada por Cierbide (2017: 15-16). 
Los cuatro nombres con mayor frecuencia designan un total de treinta y dos clérigos, lo que supone un $53.3 \%$. Salvo Sancho, el resto de los nombres coincide básicamente con el de los laicos, siendo los más habituales Juan, Pedro, Jimeno y García.

Tanto en la antroponimia masculina laica como en la clerical, conviven los nombres de origen latino trasvasados por el cristianismo (Pedro, Sancho, Juan, Domingo), los tradicionales de origen vascónico (Blasco, García, Jimeno, Eneco, Acenario) y los nombres de bautismo provenientes de la tradición germánica, previamente latinizados (Álvaro, Arnaldo, Bertrán, Ferrando, Gonzalo, Guillermo, Rodrigo). En lo que respecta a la antroponimia femenina, los nombres de bautismo son los incluidos en la Tabla 7:24

Tabla 7. Frecuencia de los nombres de bautismo femeninos.

\begin{tabular}{|l|l|c|}
\hline MARIA & Maria & 4 \\
\hline SANCTIA & Sancha, Sanya & 3 \\
\hline MARTINA & Martina & 1 \\
\hline FRANCA & Franqueta & 1 \\
\hline IOHANNA & Johana & 1 \\
\hline IURDANA & Jurdana & 1 \\
\hline TERESA & Teresa & 1 \\
\hline TOTAL & & 12 \\
\hline
\end{tabular}

Esta distribución coincide con la frecuencia general de los nombres de mujer utilizados en Ejea de los Caballeros a lo largo de toda la Edad Media (Cortés, 2019: 88-93). En este estudio, elaborado a partir de los documentos del APE comprendidos entre los años 1286-1499, se identifican un total de ciento cuarenta mujeres, siendo María el nombre más frecuente de todos (treinta y cinco mujeres, el $25 \%$ ) y Sancha el segundo más utilizado (treinta y dos mujeres, el $22.8 \%$ ). ${ }^{25}$

24 En esta relación falta una mujer que, como veremos más adelante, aparece mencionada únicamente por una designación de tipo profesional (Abadessa de Ganbron, doc. 16), como propietaria de un terreno rural.

25 El siguiente nombre de mujer más frecuente en este periodo es Toda (catorce mujeres, el $10 \%$ ). El nombre Teresa lo portan nueve mujeres en total (6\%); Juana, tres $(2.1 \%)$; Jordana, dos $(1.4 \%)$. Vid. tabla resumen en Cortés (2019: 90). En la documentación navarra de 1283 estudiada por Cierbide (2017: 


\subsection{Los apellidos patronímicos}

Con sus diversas variantes, la mayor parte de los apellidos del APE (el $62.5 \%$ del corpus) refiere el linaje familiar. Esta conclusión es válida tanto para clérigos como para hombres y mujeres. La expresión del patronímico se realiza a través de distintos procedimientos formales que pasamos a desglosar en la Tabla 8:

Tabla 8. Distribución de los apellidos de carácter patronímico.

\begin{tabular}{|l|c|c|c|c|}
\hline \multirow{2}{*}{ Procedimiento morfológico } & \multicolumn{3}{|c|}{ Apartados } & \multirow{2}{*}{ TOTAL } \\
\cline { 2 - 4 } & 3.1 & 4.1 & 4.2 & \\
\hline Sufijos gentilicios $-e z,-i z$ & 16 & 15 & 10 & 41 \\
\hline Genitivo en -i & 13 & 7 & 4 & 24 \\
\hline Adyacente preposicional & 24 & - & - & 24 \\
\hline Nombres propios como apellido & 24 & 2 & - & 26 \\
\hline TOTAL & 77 & 24 & 14 & 115 \\
\hline
\end{tabular}

Como se puede apreciar, los apellidos patronímicos formados sobre los sufijos gentilicios $-e z$, $-i z$ siguen siendo mayoritarios y representan el $22.2 \%$ del corpus. ${ }^{26}$ Los cuarenta y un apellidos formados mediante este procedimiento morfológico derivan de un stock muy reducido de diez nombres (Tabla 9):

Tabla 9. Distribución de los patronímicos en -ez, -iz.

\begin{tabular}{|l|l|c|}
\hline LUPUS & Lopeç, Lopez & 16 \\
\hline PETRUS & Pereç & 9 \\
\hline SANCTIUS & Sanç, Sanchez, Saniez & 4 \\
\hline GARCIA & Garçec & 4 \\
\hline ACENARIUS & Açnareç & 2 \\
\hline
\end{tabular}

16) también es Maria el más frecuente, seguido de Dominga, Estevania, Frontina, Sancha, Theresa, Toda y Urraca.

26 Estos son los dos únicos sufijos patronímicos gentilicios que constan en el corpus analizado frente a la notable variabilidad de la onomástica navarra medieval analizada por Cierbide (2017: 10-11) (-az, -ez, $-i z,-o i z,-u z)$. En este estudio los antropónimos de los siglos X-XI terminados en -ez, equivalen al 22.9 $\%$ del total y los terminados en $-i z$ suponen un $28.5 \%$. 


\begin{tabular}{|l|l|c|}
\hline MARTINUS & Martineç & 2 \\
\hline GALINDUS & Alinç & 1 \\
\hline FORT & Ortiç & 1 \\
\hline MUNNIUS & Moniç & 1 \\
\hline XIMENUS & Xemeneç & 41 \\
\hline TOTAL & & 1 \\
\hline
\end{tabular}

Por su parte, y en lo que se refiere a los documentos escritos en latín, el único paradigma utilizado para la formación del patronímico es el tema en -US / -I. No queda ni rastro de los patronímicos formados con los temas en -O / -ŌNIS y en -A / -ĀNIS que tan en uso estuvieron en centurias anteriores. ${ }^{27}$ Bajo este paradigma se declinan tanto los nombres tradicionales de origen latino (AEGIDIUS $>$ Egidii; PETRUS $>$ Petri; MARTINUS $>$ Martini; SANCTIUS $>$ Sancii), como los de origen vascónico (ENNECUS $>$ Eneci; LUPUS $>$ Lupii; XIMENUS $>$ Eximeni) y germánico (ADELFONSUS $>$ Alfonsi, GUILLELMUS $>$ Guillermi).

Junto a estos dos procedimientos encontramos la construcción, propiamente romance, en donde el linaje se enuncia mediante el adyacente preposicional encabezado por de, en formaciones del tipo Beltran de Feliçana, Bertrando de Johannecos, Diego de Salvador, Johannes d'Espanniol, etc. La última forma de expresión consiste en el uso de los nombres propios como apellidos (por ejemplo, Bartholomeo Gil, Beltran Gaio, Petro Beltran, Sancha Valera, Sanyo Blasco $){ }^{28}$ Aproximadamente un $14 \%$ del corpus forma parte de este grupo, situándose en el rango inferior de los promedios señalados en el siglo XIII para la Corona de Aragón, que oscilan entre el 15 y el 25 \% (Guinot, 2010: 203).

\subsection{Los apellidos toponímicos}

Como hemos anotado anteriormente, los antropónimos que contienen una indicación de de procedencia locativa ascienden a setenta y dos $(39.1 \%) .{ }^{29}$ Este dato prolonga la tendencia iniciada a finales del siglo XII en el Valle del

27 Tampoco se encuentran perífrasis latinas sustitutivas del gentilicio con filius o prolis, ni sufijos latinos de tipo -ANUS de carácter adjetival (Alvar, 1987: 117-121)

28 En algunos casos esta modalidad es el resultado de la elisión de la preposición de. Cf. Beltran de Feliçana / Dominico Feliçana; Jurdan de Roldan / Exemen Roldan.

29 Recordemos que este cómputo global resulta de la suma de los apartados $3.2+4.1$. 
Ebro, en donde el porcentaje de apellidos formados sobre indicaciones toponímicas se sitúa en torno al 32.7 \% (Laliena, 1995: 320). Asimismo, el porcentaje obtenido es homologable a la frecuencia de antropotopónimos estimada para localidades aragonesas y catalanas en el siglo XIII, «que suele estar alrededor de un tercio del total de los vecinos» (Guinot, 201: 202). ${ }^{30}$

El análisis de los lugares geográficos de los documentos del siglo XIII permite el establecimiento de cinco grupos diferenciados:

a) Antropónimos con indicación de la propia villa de Ejea (Corbaran de Exeya, Exemeno de Exeia, Garcia de Exea, Nicholaus de Exeya, Exemen Blascho de Exeya) o de los núcleos de población cercanos: Sentia (Domingo Sentia, Remigiro Sentia, Estevan Ortiç de Sentia, Pero Lopez de Sentia, Sanyo Lopeç de Sentia), ${ }^{31}$ Almalel (Maria Almalel), ${ }^{32}$ Rivas (Pelegrin de Ribas, Sanya de Ribas) ${ }^{33}$ y El Bayo (Eximenus Petri del Bayo). ${ }^{34}$

b) Antropónimos con indicación de lugares de las actuales Cinco Villas: Biota (Ferrer de Biota, Johan de Viota, Paschual de Viota, Pero Romeu de Viota), Escó (Enneco d'Esco), Isuerre (San d'Isuerre, Garçia Pereç d'Ysuerre, Michaelis Petri de Ysorre), Luna (Johannes de Luna, Exemeno Lupi de Luna, Pero Lopeç de Luna), Luesia (Matheu de Luesia), Lobera de Onsella (Miguel de Lobera), Uncastillo (Domingo d'Uncastiello, Garcia Lopeç de Uncastiello, Johan Martinę̧ d'Oncastiello) y Undués de Lerda (Pero Lopeç d'Undues).

30 Este mismo autor matiza que «cuanto más al sur esté la población, y ello es especialmente relevante cuando revisamos antroponimia de la Cataluña Nueva y el sur de Aragón, la tendencia de dicho siglo XIII es a que aumente el tanto por ciento de los antropotopónimos, incluso hasta cifras del $40 \%$ del total» (Guinot, 2010: 202).

31 El topónimo se conserva actualmente como Santia (Cortés, 2010: 195) y se localiza al este del actual término municipal de Ejea de los Caballeros. Aparece citado en la carta de población de 1110 como uno de los topónimos que conforman el perímetro (Sentia) (Cortés, 2013: 151).

32 Despoblado situado al oeste del municipio de Ejea de los Caballeros sobre una terraza fluvial del río Arba de Biel próxima al límite territorial con la villa de Luna (Cortés, 2010: 84-85). Se cita en la carta de población de 1110 como uno de los topónimos de interior (Almalel) (Cortés, 2013: 161-162).

33 Actual barrio de Ejea de los Caballeros distante cuatro kilómetros al norte del núcleo urbano (Cortés, 2010: 187). En la carta de población es una de las torres defensivas situadas junto al río Arba de Luesia (Torr de Arripas) (Cortés, 2013: 159).

34 Núcleo de población situado junto al río Riguel que fue arrasado en 1380. Aparece citado en la carta de población de 1110 como uno de los topónimos de interior (illo Bayo) (Cortés, 2013: 164-165). El antiguo nombre lo heredó uno de los núcleos de colonización de Ejea creados a raíz de la puesta en funcionamiento del Canal de las Bardenas en abril de 1959 (Cortés, 2010: 217-218). 
c) Antropónimos con indicación de lugares de la provincia de Huesca: Ahonés (Bernardi de Ahonas), Anzano (Garcia Lopeç d'Anzano), Aso (Bartholomeu d'Asso, Ferrando d'Asso, Fortunno d'Asso), Bailo (San de Baylo, Miguel Lopez de Baylo), Bergua (Garcia de Vergua), Bespén (Rodrigo Vespen), Estada (Johannis d'Estada), Gurrea de Gállego (Martinus de Gorreia), Jaca (Guillem de Iacha, Guillem de Iacha), Larbasa (Garcia Larbasa), Larués (Garcia de Larues, Sancius de Laros), Morlans (Guillermus de Morlans, Petro de Morlans) y Yebra de Basa (Johan d'Iebra).

d) Antropónimos con indicación de lugares de la provincia de Zaragoza: Cetina (Fernando de Cetina), Daroca (Johan de Darocha), Gallur (Domingo Perez de Gallur), Murillo de Gállego (Sancho Moriello) y Tarazona (Xemen de Taraçona).

e) Antropónimos con indicación de lugares del Reino de Navarra: Aldaz (Rodrigo de Aldaz), Arguedas (Johannes de Arguedas), Obanos (Teresa de Obanos), Ribaforada (Pero Ribaforada) y Sangüesa (Garçia Pereç de Sanguessa).

De estos cinco grupos se deduce la limitación geográfica de las posibles migraciones del siglo XIII que se produjeron en Ejea. ${ }^{35}$ Estas procederían de núcleos de población cercanos a la propia villa, o bien de zonas geográficas muy próximas, como las actuales Altas Cinco Villas, localidades de las provincias de Zaragoza y Huesca — en especial, de la comarca del Alto Gállegoo de Navarra. Esta «migración de corto radio» (Guinot, 2010: 202), en donde la mayoría de los topónimos procede de entornos próximos, es característica del periodo que estudiamos tanto en Aragón como en Cataluña. La única excepción a esta restricción espacial se encuentra en las personas de Estevan de Faiet (docs. 2 y 3), clérigo racionero, y Sancius de Fayet (doc. 3), cuyo topónimo remite a Fayet, población francesa de la actual región de Mediodía-Pirineos. De todos los antropónimos que contienen una indicación de lugar, trece corresponden a miembros del capítulo eclesiástico ejeano. ${ }^{36}$

35 Sobre los reparos metodológicos a esta inferencia, vid. Guinot (2010: 201-202), quien defiende el «valor indicativo geográfico» de los antropotopónimos. Para Laliena (1995: 315), estas indicaciones de procedencia cumplirían diferentes funciones, «desde fomentar las difusas solidaridades que se concretan con lentitud, hasta garantizar psicológicamente unas raíces a gentes que se mueven en un mundo extremadamente fluido».

36 De esos trece antropónimos, once corresponden a porcioneros, uno al prior Exemeno Lupi de Luna (1273) y el otro al sacristán Exemeno de Exeia (1243). La distribución geográfica de estos clérigos está 


\subsection{Otras modalidades de apellidos}

Al margen de los apellidos de carácter patronímico y toponímico, cabe destacar la escasa presencia en la antroponimia del APE de otras modalidades habitualmente empleadas en la formación del apellido (el $4.3 \%$ del corpus). Así, solo cuatro personas presentan un apellido basado en el nombre de un oficio (Adam Caçinero, doc. 21; Lop Capellan, doc. 21; Pero Ferrero, docs. 9, 10, 14; Sancius Ortolano, doc. 3) (Frago, 1977). Por otra parte, son escasos los apellidos basados en el parentesco (Garcia Sobrino, doc. 9; Pero Sobrino, docs. 5, 9, 10, 11 y 18), en rasgos físicos (Dominico Ezquerrer, doc. 3) y en la naturaleza (Blascho Balles, docs. 9 y 10). Y, por último, son indetectables los apellidos basados en apodos u otras formas de cognominación (Frago, 1976), en rasgos morales, en objetos y en la hagionimia. ${ }^{37}$

\section{Los clérigos}

Dada la naturaleza del archivo y de los hechos registrados en la documentación, un porcentaje muy significativo de los antropónimos se refiere a hombres de Iglesia: sesenta antropónimos del corpus analizado corresponden a personas vinculadas con la institución eclesiástica (el $32.6 \%$ del corpus). ${ }^{38}$ La distribución segregada de la antroponimia eclesiástica en función de la forma utilizada arroja un reparto porcentual muy similar al de la antroponimia laica (Tabla 10):

Tabla 10. Clasificación de la antroponimia eclesiástica.

Datos directos agrupados y porcentuales.

\begin{tabular}{|l|c|c|}
\hline Estructuras & Número & $\%$ \\
\hline 1. Nombre único & 1 & $1.6 \%$ \\
\hline 2. Nombre + designación complementaria & - & - \\
\hline 2.1. Hijo de & - \\
\hline
\end{tabular}

bastante repartida: tres pertenecen al grupo (a), cuatro al grupo (b), tres al grupo (c), uno al grupo (d) y dos al grupo (e).

37 Estos datos corroboran otra tendencia general apuntada en los estudios antroponímicos de la Corona de Aragón en el siglo XIII: «la progresiva desaparición hacia mitad de centuria de las formas más peculiares de identificación» (Guinot, 2010: 200).

38 Queda exceptuada de este cómputo la Abadessa de Ganbron que interviene en el documento 16 en calidad de propietaria. 


\begin{tabular}{|c|c|c|}
\hline 2.2. Otra relación familiar & - & - \\
\hline 2.3. Nombre + designación de tipo profesional & 2 & $3.4 \%$ \\
\hline \multicolumn{3}{|l|}{ 3. Formas antroponímicas de dos elementos } \\
\hline 3.1. Nombre + patronímico & 24 & $40 \%$ \\
\hline 3.2. Nombre + toponímico & 12 & $20 \%$ \\
\hline 3.3. Nombre + otras indicaciones & 4 & $6.6 \%$ \\
\hline \multicolumn{3}{|l|}{ 4. Formas complejas } \\
\hline 4.1. Nombre + patronímico + indicación de lugar & 10 & $16.7 \%$ \\
\hline 4.2. Nombre + patronímico + indicación familiar & 7 & $11.7 \%$ \\
\hline Total & 60 & $100 \%$ \\
\hline
\end{tabular}

En este apartado vamos a analizar más en detalle la información que la antroponimia aporta al estudio histórico de la iglesia en Ejea a lo largo del siglo XIII. Pero antes vamos a dar una breve noticia de lo que conocemos sobre los estadios anteriores al año 1241. La iglesia de Ejea estuvo vinculada desde sus orígenes con la abadía de Santa María de la Selva Mayor ${ }^{39}$ y, «aunque fue durante algunos años objeto de disputa entre los obispados de Pamplona y Zaragoza, en 1155 pasó definitivamente a la diócesis zaragozana» (Lomax, 1986: 497; Pavón, 2007: 199-201). A comienzo del siglo XIII, concretamente en 1204, el priorato de Ejea estaba compuesto por dieciséis prebendarios que se distribuían de la siguiente manera: ocho sacerdotes, cuatro diáconos y cuatro subdiáconos ${ }^{40}$ Hacia 1240 — es decir, justo en el término a quo de nuestro estudio- este priorato, en palabras de Lomax (1986: 501) «estaba en franca decadencia». Esto se refleja en los distintos acuerdos a los que se llegó en esa fecha para pagar las deudas del priorato.

39 Como es sabido, en 1084 y 1086 el rey Sancho Ramírez concedió las mezquitas y diezmos de Ejea a este monasterio fundado en 1079 por san Gerardo bajo la protección de Guillermo VIII de Aquitania. (vid. Canellas, 1993, doc. 73 y doc. 91 respectivamente). Como señala Lomax (1986: 497), «Ejea llegó pronto a ser la casa principal de La Selva en España». Según consta en el acta de consagración de Santa María de 1174 (DAPE, doc. 1; recogida también en Monterde, 2006: 394-395), en el acto litúrgico de consagración de Santa María estuvo presente Ricardo, prior mayor del monasterio de la Selva Mayor. También se deja constancia de la presencia en el acto de otros monjes de este monasterio (aliique monachi de eodem monasterio de Silva Maiori).

40 Según el documento fechado el 1 de agosto de 1204 por el que Grimoaldo, abad de La Selva y obispo de Comminges, promulga estatutos para el priorato de Ejea. El documento se recoge en el apéndice (doc. 10) del artículo de Lomax (1986: 505). 
El entonces prior de Ejea, Elías, que actuaba en representación de Radulfo, abad de Santa María de la Selva Mayor, vendió Villanueva de Huerva a Sancho de Sesse y su esposa Teresa Puig, siendo fiador Juan de Lográn, que aparece como testigo y clérigo racionero en el documento 2 del APE (Johan de Logran). Este mismo clérigo recibió en usufructo del abad de Santa María de la Selva Mayor la casa de Santa María de Argilate y también «la casa entera de Ejea, con todas sus dependencias, y con permiso de vender o empeñar sus propiedades hasta un máximo de valor de mil maravedís, para pagar las deudas de la casa» (Lomax, 1986: 501). Asimismo, Juan de Lográn se comprometió «a mantener decentemente el servicio divino en el convento de Ejea» y también a «pagar los gastos personales, cuidadosamente estipulados, de un prior, dos monjes y varios dependientes» (Lomax, 1986: 501). En definitiva, este acuerdo "permitió que el priorato siguiese existiendo, pero en una situación que contrastaba muy desfavorablemente con la descrita en 1204 por Don Grimoaldo, abad de la Selva y obispo de Comminges» (Lomax, 1986: 501). ${ }^{41}$

\subsection{El capítulo de la iglesia de Ejea}

El estudio de la antroponimia del APE permite identificar el nombre de dos priores, ya en el último tercio del siglo XIII: Exemeno Lupi de Luna (1273) y Petro de Trillis (1277). El nombre del primer vicario nos ha llegado incompleto: [...] Gorreia (1241). En 1274 figura Pero Ferrero, que lo sigue siendo en 1283 y que actúa además como procurador de los clérigos racioneros. De 1279 a 1299 el vicario es Alvaro.

En los documentos constan las capellanías de Alvaro (1241) - al que acabamos de citar-, Michael de Salvador (1241), Exemen Lopez de Mallada (1297), Martin Suari (1299) y Miguel Lopez (ca. 1300). En los casos de Michael de Salvador (doc. 2), Martin Suari y de Miguel Lopez, consta expresamente que ejercen como capellanes de Santa Maria de Exeya (doc. 21). Conocemos también el nombre de dos sacristanes. El primero es Eximeno de Exeia (1243); el segundo es Pero Lopeç de Uchando, que aparece como tal en 1279 y lo sigue siendo en 1299.

Con respecto a la evolución de la abadía de Santa María de la Selva Mayor en las Cinco Villas, y tras subrayar el «mayor arraigo» que tuvo en Ejea, Piedrafita (2007: 279) concluye: «Convertida en una orden militar, se advierte cierto interés en "liquidar" las propiedades en esta comarca, viviendo un período de ventas y permutas de bienes hasta fines del siglo XIII». 
Los documentos analizados permiten identificar entre 1241 y 1299 un total de cuarenta y dos clérigos racioneros. En el anexo II del trabajo se distribuyen todos estos nombres a lo largo de los años. Los documentos 2,11 y 21 relacionan la nómina completa de los clérigos racioneros que componían el capítulo en los años 1241, 1277 y 1299 respectivamente. De estas nóminas se deduce que el capítulo de la iglesia de Ejea en la segunda mitad del siglo XIII estuvo formado por un vicario y un número variable de clérigos racioneros que oscila entre los doce censados en $1241,{ }^{42}$ los diecisiete en 1277 y los dieciséis en 1299. De entre todos estos clérigos racioneros destacan Beltran de Hoç y Açnar Alinç. Ambos figuran en los capítulos de 1277 y 1299; el primero ejerce además como procurador de los porcioneros desde 1274. En cuanto a los clérigos no racioneros, conocemos a seis de ellos: Blascho Balles (docs. 9, 10), Johan Lopeç d'Espanyol (docs. 9, 10), Pero Pereç (doc. 9), Pero Sobrino (docs. 5, 9, 10, 18), Rodrigo Vespen (doc. 9) y Sanchio d'Ardiles (docs. 9, 10, 13, 14); este último actúa como procurador de todos ellos en la cuestión suscitada.

Cabe señalar, por último, tres casos especiales que no pertenecen propiamente al capítulo de la iglesia de Ejea, pero sí forman parte de la comunidad religiosa de la villa. Son los casos de fray Fernando de Cetina (doc. 9), fray Rodrigo de Aldaz y fray Johan Martineç d'Oncastiello (doc. 13). El primero actúa como árbitro en el pleito sobre el reparto de raciones (1274) y los otros dos figuran como testigos en el pleito con los clérigos de Biota (1279). Todos ellos tienen en común su pertenencia a la orden de los Frailes Menores de Ejea. Es decir, formaban parte de la comunidad del convento de San Francisco fundado extramuros de la villa de Exea, al otro lado el río Arba, en torno a la antigua ermita de San Matías; los dos primeros, además, son guardianes de la orden. Según los datos proporcionados por el cronista oficial de la villa José Ferrer (1790 [1999]: 152), este convento, que en la primavera de 1265 alojó las Cortes en donde se instituyó la figura del Justicia de Aragón, fue fundado en el año $1235 .{ }^{43}$ Nótese cómo los tres antropónimos portan una indicación de lugar (Cetina, Aldaz, Uncastillo).

42 Este dato de doce porcioneros en 1241 obliga a matizar la afirmación de Lomax (1986: 501) de que el priorato de Ejea «estaba en franca decadencia» hacia 1240, época en la que se producen las ventas que hemos comentado.

43 Ferrer se basa en la crónica de fray José Antonio Hebrera: «el Convento de San Francisco de Exea estaba ya fundado en mil doscientos treinta y cinco». No obstante, antes de este pasaje Ferrer (1790 [1999]: 151-152) anotó: «En este sitio, fuera del comercio de la gente, aunque a corta distancia, fundaron el convento para nuestros Religiosos antes del año mil doscientos sesenta y cinco». 


\subsection{Eclesiásticos de otras diócesis y lugares}

Aunque han sido excluidos del corpus antroponímico analizado, vamos a realizar un pequeño apunte caracterizador del sector eclesiástico que procede de otras diócesis y localidades. Son, en total, diecisiete antropónimos. Doce de estos nombres personales corresponden a autoridades encargadas de intervenir en el conflicto que mantienen los clérigos racioneros y no racioneros del capítulo de la iglesia ejeana. De todos ellos destacan Gil de Lopinnen, arcediano de Teruel y oficial de Zaragoza (docs. 9 y 10); Johan Pereç de Falçes, arcediano de Val de Aibar y juez delegado de la Corte de Tarragona (docs. 9 y 10); y Pero Pereç d'Ayerbe, canónigo de Zaragoza (doc. 9). Son los tres árbitros enviados por Pero, obispo de Zaragoza, para ejercer como árbitros en la disputa. Otras autoridades también participan en la resolución de este pleito y muchas de ellas proceden de la diócesis de Pamplona, como los canónigos Petro Sancii de Huart —que actúa también como notario de esta diócesis-, Martino Eguidii de Falabus y Rodericus Guillermi (todos ellos citados en el doc. 8). ${ }^{44}$

Además de los anteriores, entre los eclesiásticos ajenos a la iglesia de Ejea se incluyen otras dos personas. La primera es la Abadessa de Ganbron (doc. 16), monasterio cisterciense situado en la villa de Sádaba (Cinco Villas, Zaragoza), ${ }^{45}$ que en 1286 aparece como propietaria de un campo confrontante en Ejea. La segunda es Johan d'Onanovença (doc. 18), clérigo de Biota, que interviene como procurador en el pleito que la iglesia de esta localidad mantiene con la de Ejea por el poralmario de Ferrando d'Asso y su esposa Maria Almalel.

\section{Los laicos}

Son ciento veinticuatro las personas laicas del corpus analizado (67.3\%). Dentro de este colectivo se distinguen varios grupos que pasamos a comentar.

44 Garsias Petri, arcediano de Eguiart (doc. 8), Johan Lopeç, abad de Anzano (doc. 9), Lopus Martini Laviano, prior de Belath (doc. 8), Michaeli de Monte Acuto, testigo y guardián de la orden de los Frailes Menores de Valencia (doc. 11), y Vitalis de Cabanato, procurador de las diócesis de Pamplona y Zaragoza, así como del monasterio de Selva Mayor (doc. 11), que es la persona encargada de redactar el fallo sobre la cuestión suscitada.

45 El monasterio cisterciense de la Concepción de la Virgen de Cambrón, del que todavía quedan algunos restos, fue ocupado en 1212 por monjas procedentes del monasterio de Santa María de Iguácel (Larrosa, Jacetania) (Cortés, 2010: 104-105). Sobre la historia de este monasterio, vid. los trabajos de Pérez Guzmán y Jiménez Acín (1983: 24-33) y de Asín (2000: 98-109). 
El primer grupo está formado por aquellas personas que desempeñan un cargo en la organización civil de la villa. De entre ellos, el más relevante es el Justicia de Ejea Garcia Larcas, que en 1286 (doc. 16) condena a Maria Sanchez, viuda de Martin de Alaman, a la devolución de una viña al capítulo de la iglesia de Ejea tras el incumplimiento del treudo. ${ }^{46}$ Anteriormente, en septiembre de 1277, Garcia Larcas también había intervenido como testigo en el pleito sobre el reparto de raciones del capítulo ejeano (doc. 11). En este mismo proceso de incumplimiento del treudo interviene Domingo Sanç, baile de la corte de Ejea (doc. 16), que es el encargado de cursar las citaciones a Maria Sanchez para comparecer ante dicha corte. ${ }^{47}$ Además, la documentación refiere la presencia de Pero Romeu de Viota, cavero (doc. 9), y Sanyo Blasco, corredor (doc. 19).

En un segundo grupo se encuentran aquellas personas, todos ellos vezinos de Exea, que actúan como fiadores, testigos, cabezaleros o espondalarios en los actos jurídicos sancionados por los documentos. ${ }^{48}$ Entre ellos cobra un especial relieve la presencia de algunos varones de Ejea, prohombres de la villa que hacen valer su condición de milites: Garcia Larbasa (doc. 6), Garcia de Larues (docs. 6, 7), Petrus Senebucy (doc. 11) y Petrus Suario (doc. 11). En dos de los que actúan como testigos consta su condición de escuderos (scutiferi): Açnarius Eneci (doc.11) y Petrus Sancii de Peruxa (doc. 11). El tercer grupo lo forman los propietarios - treinta y cinco en total - citados en las afrontaciones de campos, viñas y casas de las que se venden o donan. El último grupo está formado por aquellas personas que no participan directamente de los actos documentales y sirven como designación complementaria al nombre expresando una relación familiar (por ejem-

46 Esta viña estaba situada en la partida de Camarales y era propiedad de los clérigos racioneros de la iglesia de Ejea. Como contrapartida el matrimonio había adquirido una serie de compromisos. En primer lugar, el día de San Miguel de cada año tenía que pagar a los clérigos racioneros tres sueldos jaqueses. En segundo lugar, se comprometía a su mantenimiento y a podarla todos los años. Por las razones que fuesen, Maria Sanchez no cumplió este acuerdo y el capítulo de los clérigos ejeanos denunció el incumplimiento.

47 Domingo Sanç citó a Maria Sanchez un jueves, pero ni ella ni ningún procurador en su nombre se presentaron ante el Justicia. Volvió a citarla el viernes, con el mismo resultado. La volvió a citar el sábado y tampoco compareció. En vista de todo lo anterior, el Justicia de Ejea la juzgó contumaz y condenó a Maria Sanchez a pagar una multa de nueve sueldos jaqueses, a restituir el daño ocasionado por la falta de mantenimiento de la viña y a quitarle el arriendo de la misma según fuero de Aragón.

48 En total, dieciséis fiadores, cuarenta y un testigos, los tres albaceas que intervienen en la venta de una viña al capítulo de los clérigos racioneros (doc. 4) y los dos espondalarios que figuran en el único testamento analizado (doc. 20). 
plo, Dominice Çafari, marido ya fallecido de Maria, doc. 4; Dominici Lupii, padre de Johannes Luppi, doc. 5).

En lo que respecta al grupo de mujeres mencionadas en la documentación, cabe señalar que seis de ellas se citan como esposas del marido que interviene en el acto jurídico (muller de..., muller que fue...) y una de ellas como hija (nuestra filla); las seis restantes aparecen como propietarias de distintos campos o viñas confrontantes.

Como hemos anotado anteriormente (§ 2.3), en la documentación analizada son muy escasas las anotaciones referidas a oficios al margen de los ya citados en la organización civil de la villa. La única persona de la que se refiere su oficio es Sancho Pereç, adobador (doc. 21). Mención aparte merecen los notarios y escribanos que participan en la escritura de los documentos. Salvo dos notarios que proceden de otros lugares e instancias eclesiásticas para intervenir en los conflictos $\operatorname{suscitados},{ }^{49}$ el resto son escribanos y notarios de la propia villa. ${ }^{50}$ En los primeros documentos figuran como escribanos Guillermus de Exea (doc. 2) y Guillermus de Iacca (doc. 3). En la venta de agosto de 1254 Sancius Egidii, notario público de Exea, sustituye a Johannes Petri Sobrini, que en ese momento se encontraba gravemente enfermo (doc. 4). ${ }^{51}$ Los notarios con mayor antigüedad son Johannis Marquesii, cuya ejecutoria se atestigua entre 1256 y 1274 , y Domingo Feliçana, cuya primera firma aparece en 1277 y sigue en ejercicio en 1299.

\section{Las indicaciones sociales}

En este apartado vamos a considerar las indicaciones sociales que acompañan a los antropónimos exponiendo primeramente los datos obtenidos. Además de la condición de milites y scutiferi que acabamos de citar, nos vamos a detener en la indicación don, dominus, dona, domina.

En lo que respecta a los miembros de la Iglesia, veinticuatro de los sesenta clérigos reciben la distinción don, dominus (40\%). Recae de manera invaria-

49 Petro Sancii de Huart, notario público de la diócesis de Pamplona (doc. 8), e Ispanus, notario del Obispo de Zaragoza (doc. 14).

50 La relación detallada de todos ellos en su secuencia cronológica se incluye en el anexo III del trabajo.

51 Quando hec carta fuit escripta Johannes Petri Sobrini escriptor publicus Exeya erat graviter infirmus (doc. 4). 
ble sobre los vicarios, priores y capellanes, pero alterna entre los clérigos racioneros y no racioneros, según el documento. Esta misma indicación la reciben sesenta y dos de los ciento once hombres (55.8 \%): trece de los dieciséis fiadores; veintitrés de los cuarenta y un testigos; uno de los tres albaceas; veintitrés de los treinta y cinco propietarios; y los dos espondalarios. En lo que respecta a la antroponimia femenina, siete de las trece mujeres reciben la indicación dona, domina (53.8\%). Como se puede apreciar, estas fluctuaciones que se observan entre la presencia y ausencia de esta designación parecen responder más a la scripta notarial que a una designación real del estatus que ocupa la persona en esa sociedad, lo que no permite deducir unas inferencias claras más allá de lo ya expuesto en líneas anteriores.

En este contexto queremos señalar, por incidir directamente en el periodo cronológico analizado, la confusión que reinaba en Ejea en la segunda mitad del siglo XIII con respecto a la pertenencia real o fingida de algunos individuos a la baja nobleza. Esta confusión provocó la intervención del rey Jaime I de Aragón, quien en 1257 envió a la villa de Ejea a su portero Bernardo de Sigena para que actuara contra los que se proclamaban infanzones en esta villa sin serlo (illos homines nostros de Exeya qui non debent esse infanciones), instando a sus caballeros e infanzones de confianza (Iacobus et cetera, dilectis suis universis militibus et infancionibus de Exeya, salutem et dilectionem) para que de una vez por todas tomaran cartas en un asunto que al rey le parecía de extrema gravedad (quod nobis displicet plurimum et est grave). ${ }^{52}$ Conocemos también que el 20 de noviembre de 1278, «ante la proliferación de presuntos infanzones en Ejea, Pedro III ordenó a Pedro de Casbas que obligara a todos los habitantes que pretendieran ser infanzones a que probaran su condición mediante la correspondiente salva, según disponían los Fueros de Aragón» (Falcón, 2017: 298). ${ }^{53}$

\section{Conclusiones}

El Archivo Parroquial de Ejea de los Caballeros es la principal fuente documental para el análisis del estadio más antiguo de la antroponimia de esta

52 Cabanes (2007: 131, doc. 103) y Falcón (2008: 106, doc. 3). La comunicación, intitulada Littera peremptoria militibus et infançionibus de Exea super emparamento illorum que debunt peytare, lleva fecha del 6 de agosto de 1257 y está dada en la ciudad de Lérida.

53 Ninguno de los veintitrés habitantes de Ejea que, tras realizar la salva correspondiente, obtuvo su infanzonía entre los años 1243-1330 (Falcón, 2003, 2008 y 2007: 312, apéndice III) aparece mencionado en los documentos del APE que han sido objeto del estudio. 
villa zaragozana. En este trabajo se han analizado los nombres personales de los veinte documentos comprendidos entre los años 1241-1299. A este respecto, hay que tener en cuenta que, entre la concesión por parte de Alfonso I de la carta de población a la villa (1110) y el primero de los documentos analizados (1241), se extiende un periodo de ciento treinta años de vacío documental. Este vacío - solo interrumpido por el acta de consagración de la iglesia de Santa María en 1174- restringe notablemente la posibilidad de conocer la antroponimia de la villa durante el siglo XII y trazar un estudio evolutivo.

El corpus neto analizado asciende a ciento ochenta y cuatro antropónimos, de los cuales ciento once corresponden a hombres $(60.3 \%)$, sesenta a clérigos $(32.6 \%)$ y trece a mujeres $(7.1 \%)$. En el sistema antroponímico descrito las personas se individualizan a través de dos nociones básicas: el linaje familiar y el lugar de origen. Estos resultados coinciden con las tendencias generales de la antroponimia de la Corona de Aragón en el siglo XIII señalada por otros estudios elaborados a partir de censos (Guinot, 2010: 199).

El análisis de las diversas estructuras empleadas en la formación de los antropónimos muestra el predominio de estructuras antroponímicas formadas por dos elementos $(72.3 \%)$, siendo la más representativa de la antroponimia de Ejea de los Caballeros en el siglo XIII la formada por nombre + patronímico $(41.4 \%)$. En un segundo nivel, se encuentran las estructuras complejas trimembres $(21.2 \%)$. Por su parte, las formas antroponímicas compuestas por un nombre único $(2.7 \%)$ y por un nombre acompañado de una designación complementaria de carácter familiar o profesional $(3.8 \%)$ son irrelevantes.

En lo que se refiere a los nombres de bautismo, en el repertorio de nombres masculinos conviven los nombres de origen latino incorporados a la tradición cristiana (Domingo, Juan, Martín, Miguel, Pedro, Sancho), que son mayoritarios, con los de origen vasco, que tanta importancia tuvieron en los dos siglos anteriores (Acenario, Eneco, García, Jimeno), y los nombres germánicos (Arnaldo, Beltrán, Bernardo, Ferrando, Guillermo). Los nombres más frecuentes de los varones ejeanos durante el siglo XIII son Sancho, Domingo, Juan, Pedro, Jimeno y García. Este stock de estos seis nombres supone el $62.1 \%$ en el caso de los laicos. Juan, Pedro, Jimeno y García son también los más usados entre los clérigos. En lo que respecta a las mujeres, y si bien la dispersión es mayor, los dos nombres más representativos son María y Sancha. 
En la formación de los apellidos patronímicos son mayoritarios los formados sobre los sufijos $-e z$, $-i z(22.2 \%)$. En segundo lugar, se encuentran los que utilizan los nombres propios como apellidos (14\%) y los apellidos formados con la construcción romance encabezada por la preposición de (13\%). En aquellos documentos escritos en latín el patronímico se declina únicamente mediante el genitivo de los temas en -US / -I.

El análisis de las indicaciones de lugar contenidas en los antropónimos del corpus examinado dibuja un marco espacial muy limitado. Estos lugares se reparten básicamente en dos áreas geográficas: por un lado, los núcleos poblacionales cercanos a Ejea (Almalel, El Bayo, Rivas, Sentia) y localidades pertenecientes a las actuales Cinco Villas (Biota, Escó, Isuerre, Lobera de Onse1la, Luesia, Luna, Uncastillo, Undués de Lerda); por otro, localidades de las provincias de Zaragoza y Huesca — principalmente de la comarca del Alto Gállego-y de la comunidad limítrofe de Navarra.

La hegemonía de los apellidos patronímicos y toponímicos contrasta con la escasa presencia de designaciones de tipo profesional o parentesco $(4.3 \%)$, así como la ausencia prácticamente absoluta de apellidos basados en apodos u otras formas de cognominación (rasgos físicos y morales, objetos).

Desde el punto de vista social, y en lo que se refiere a la antroponimia laica, el estudio proyecta básicamente una visión de los caballeros de Ejea en el siglo XIII. Son los que ocupan los principales cargos en la organización de la villa, los que intervienen en asuntos relevantes y los que poseen bienes urbanos (barrio de San Salvador) y propiedades rurales en la huerta vieja de la villa que está situada junto a los dos brazos del río Arba (Camarales, Facemón, Luchán, Madriguera). La intervención del rey Jaime I para actuar contra los falsos nobles e infanzones en agosto de 1257, y posteriormente la del rey Pedro III en 1278 por este mismo motivo, revela una comunidad en donde la adscripción a determinadas posiciones nobiliarias se prestaba a toda clase de imposturas.

Por último, hay que señalar que la antroponimia de los documentos estudiados no ha permitido detectar la presencia de contingentes repobladores específicos (francos, vascones, etc.) en Ejea de los Caballeros, como ocurre en otras poblaciones (Alvar, 1965-1966) o áreas geográficas (Guinot, 2010; Remedios, 2014; Cierbide, 2017) por estas mismas fechas. 


\section{Anexos}

Anexo 1. Relación de antropónimos procedentes de los documentos del siglo XIII del Archivo Parroquial de Ejea de los Caballeros. ${ }^{54}$

Abadessa de Ganbron: 16 (propietaria)

Acach: 4 (propietario, hijo de Arnaldi Hera)

Açnar Alinç, don: 11 (Aznarius Alinç), 21 (clérigo racionero de Ejea)

Açnar de Barçac, don: 9 (fiador)

Açnarius Eneci: 11 (testigo y scutiferus)

Adam Caçinero, don: 21 (clérigo racionero de Ejea)

Alvaro, don: 13, 15, 18, 21 (vicario de Ejea)

Arnaldi de Hera: 4 (propietario, finado)

Arnalt, don: 13 (testigo y vecino de Ejea)

Aznar Lopez: 2 (testigo y clérigo racionero de Ejea)

Bartholomeo Gil: 16 (escribano de la corte de Ejea)

Bartholomeu, don: 21 (clérigo racionero de Ejea)

Bartholomeu d'Asso: 12 (testigo), 13 (fiador) (vecino de Ejea)

Bartholomeu del Farno, don: 11, 21 (clérigo racionero de Ejea)

Beltran de Feliçana, don: 9 (promicero), 16 (testigo)

Beltran de Hoç, don: 10, 11 (Bertrandus de Hoç), 12, 16, 21 (clérigo racionero de Ejea y procurador de los clérigos racioneros de Ejea)

Beltran Gaio, don: 2 (testigo y clérigo racionero de Ejea)

Bernardi de Ahonas, dompnus: 4 (propietario)

Bertrando de Johannecos: 3 (propietario)

Blascho Balles, don: 9, 10 (clérigo no racionero de Ejea)

Boneti Marçaris, dompnus: 5 (propietario)

Corbaran de Exeya, don: 15 (fiador)

Diego de Salvador, don: 9, 10 (fiador)

Domingo d'Uncastiello: 20 (propietario)

54 Los antropónimos se disponen por orden alfabético, incluyendo el tratamiento, si así consta en la documentación. Tras los dos puntos figura el número del documento en donde se mencionan. Entre paréntesis y en cursiva se anota el nombre latino en aquellos casos en donde se producen duplicidades. Entre paréntesis y en redonda se anotan los datos de identificación que se han podido obtener. La forma aferética Xemen se incluye a continuación de las formas plenas Exemen, Exemeno o Eximeno. 
Domingo Feliçana: 2 (hermano de Sanio Feliçana), 11 (Dominicus Feliçana), 16, 20 (Dominici Feliçane), 21 (Dominico Feliçano) (notario público de Ejea)

Domingo Moniç: 20 (testigo y vecino de Ejea)

Domingo Perez de Gallur: 18 (testigo y vecino de Ejea)

Domingo Sanç: 16 (baile de la corte de Ejea)

Domingo Sentia el Mayor, don: 9 (fiador)

Dominice Çafarie, dompnus: 4 (marido de Maria, finado)

Dominici Lupii: 5 (padre de Johannes Luppi)

Dominico de Polo: 2 (testigo)

Dominico Ezquerrer: 3 (comprador)

Dominicus Pastoris, dompnus: 4 (cabezalero)

Domisanç del Forno, don: 20 (espondalero)

Egidio de Biasos, don: 2 (testigo y clérigo racionero de Ejea)

Egidius Garcez 5, 10 (notario público de Ejea)

Enego Xemenez: 20 (propietario)

Eniego Martineç: 11 (Ennecus Martini), 12,13, 19 (Eniego Martinici) (notario público de Ejea)

Enneco d'Esco: 18 (testigo y vecino de Ejea)

Estevan de Faiet, don: 2, (testigo y clérigo racionero de Ejea), 3 (Stephanus de Fayet)

Estevan Ortiç de Sentia, don: 19 (testigo y vecino de Ejea)

Exemen Blascho de Exeya, don: 10 (árbitro)

Exemen de Noguera, don: 10 (testigo)

Exemen Lopez de Mallada: 20 (Xemen Lopeç de Mallada, capellán), 21

(clérigo racionero de Ejea)

Exemen Roldan, don: 12 (testigo y vecino de Ejea)

Exemeno d'Ardiles, don: 19 (testigo y vecino de Ejea)

Exemeno de Avero: 2 (testigo y clérigo racionero de Ejea)

Exemeno de Exeia: 3 (sacristán)

Exemeno Lupi de Luna, domino: 8 (prior)

Eximeno Luppi, dompnus: 5 (hermano de Johannes Luppi)

Eximeno Petri Abbul: 11 (clérigo racionero de Ejea)

Eximenus Petri del Bayo: 11 (clérigo racionero de Ejea)

Xemen de Taraçona, don: 15 (testigo y vecino de Ejea)

Xemen Pereç don Abril: 15 (clérigo racionero de Ejea) 
Fernando de Cetina, fray: 9 (guardián de los Frailes Menores de Ejea y árbitro)

Ferran d'Albaro, don: 12 (clérigo racionero de Ejea)

Ferrando d'Asso, don: 18 (marido de Maria Almalel)

Ferrer de Biota, don: 18 (testigo y vecino de Ejea)

Fortunius de Alvero: 8, 11 (clérigo racionero y procurador de los clérigos racioneros de Ejea)

Fortunno d'Asso, don: 10 (testigo)

Franqueta: 20 (hija de Sancho Lopeç de Vrez y Maria Lopeç)

Frotum, don: 15 (testigo y vecino de Ejea)

Garcia Açnareç, don: 20 (propietario)

Garcia de Exea: 2 (escribano)

Garcia de Larues, dompnus: 6, 7 (testigo, milites)

Garcia de Val, don: 9 (clérigo y testigo)

Garcia de Vergua, don: 15 (propietario y marido de Martina)

Garcia Larbasa, dompnus: 6 (testigo, milites)

Garcia Larcas, dominus: 11 (testigo), 16 (Justicia de Ejea)

Garcia Lopeç d'Anzano, don: 12 (propietario)

Garcia Lopez de Barcach: 21 (clérigo racionero de Ejea)

Garcia Lopeç de Mallada, don: 9 (fiador), 10 (testigo)

Garcia Lopeç de Uncastiello, don: 10 (testigo)

Garçia Pereç de Lera, don: 21 (propietario)

Garçia Pereç de Sanguessa: 15 (clérigo racionero de Ejea)

Garçia Pereç d'Ysuerre, don: 11 (Garsias Petri de Isorre), 21 (clérigo racionero de Ejea)

Garçia Petri don Peronet: 10 (fiador), 11 (clérigo racionero de Ejea)

Garcia Sobrino, don: 9, 10 (fiador)

Garsias Egidii: 17 (presbítero de Ejea)

Garsias Luppi de Sant Iohanne: 6, 7 (hermano de Pero Lopeç de Uchando, fiador)

Garsias Sancii de Sancti Stefani, dompnus: 6, 7 (padre del sacerdote Pero Lopeç de Uchando, finado)

Gatan Açnar: 20 (propietario), 21 (testigo, vecino de Ejea e hijo de Paschual de Viota)

Gil Garçec, don: 9 (testigo y escribano público de Ejea)

Gil Perez de Senebrio: 20 (propietario) 
Gonzalbus Luppi de Gradibus: 11 (clérigo racionero de Ejea)

Guillem de Iacha: 2 (testigo), 3 (Guillermus de Iacca, escribano)

Guillem de Jacha: 21 (clérigo racionero de Ejea)

Guillermus de Morlans: 11, 12 (Guillem de Morlans) (clérigo racionero de Ejea)

Johan Arias: 20 (propietario)

Johan de Berdellio, don: 9 (fiador)

Johan de Darocha: 2 (testigo), 11, 12 (clérigo racionero de Ejea)

Johan de Logran: 2 (testigo y clérigo racionero de Ejea)

Johan de Sant Iuan: 2 (testigo y clérigo racionero de Ejea)

Johan de Viota: 21 (clérigo racionero de Ejea)

Johan d'Iebra: 18 (testigo y vecino de Ejea)

Johan Garcez d'Ortinyones: 18 (notario público de Ejea)

Johan Lopeç d'Espanyol, don: 9, 10 (clérigo no racionero de Ejea)

Johan Martineç d'Oncastiello, fray: 13 (testigo)

Johan Pereç de Santacruz, don: 21 (clérigo racionero de Ejea)

Johana Barçach: 20 (propietaria)

Johannes Artus: 17 (vicario de Ejea)

Johannes de Arguedas: 11 (clérigo racionero de Ejea)

Johannes d'Espanniol: 2 (diácono), 5 (Iohannus d'Espanniol, fiador), 11

(clérigo racionero de Ejea)

Johannes de Luna: 5 (testigo)

Johannes Eximeni: 11 (clérigo racionero de Ejea)

Johannes Lupii, dompnus: 5 (donante, hijo de Dominici Luppi, finado)

Johannes Petri Sobrini: 4 (notario público de Ejea, enfermo de gravedad)

Johannis d'Estada, dompnus: 4 (propietario)

Johannis Marquesii: 5, 6, 7, 9 (notario público de Ejea)

Jurdan de Roldan: 20 (propietario)

Jurdana Berne: 20 (propietaria)

Lop Capellan, don : 21 (testigo, vecino de Ejea e hijo de Sancho Pereç)

Maria, dompna: 4 (viuda de Dominice Çafarie, cabezalera)

Maria Almalel, dona: 18 (mujer de Ferrando d'Asso)

Maria Lopeç: 20 (mujer de Sancho Lopeç de Vrez)

Maria Sanchez, dona: 16 (mujer de Martin de Alaman, finado) 
Martin de Alaman, don: 16 (marido de Maria Sanchez, finado)

Martin Marques: 21 (clérigo racionero de Ejea)

Martin Suari, don: 10 (clérigo racionero de Ejea y procurador de los clérigos racioneros de Ejea), 21 (capellán mayor de la iglesia de Santa María de Ejea)

Martina, donna: 15 (mujer de Garcia de Vergua)

Martinus de Gorreia: 2 (testigo y hermano de don Valero, capellán)

Martinus Luppi de Gradibus, dompnus: 4 (cabezalero)

Matheu de Lusia, dompnus: 6 (propietario), 10 (Matheu de Luesia, fiador)

Michael de Salvador: 2 (testigo y capellán de Santa María de Ejea)

Michaelis Marquesii: 15, 17 (notario de Ejea)

Michaelis Petri de Ysorre, dompnus: 5 (propietario)

Miguel d'Ardiles, don: 9, 10 (fiador)

Miguel de Lobera: 20 (propietario)

Miguel Lopeç, don: 18 (testigo y capellán de la iglesia de Santa María de Ejea)

Miguel Lopez de Baylo: 21 (clérigo racionero de Ejea)

Nicholaus de Exeya, dompnus: 4 (testigo)

Paschual de Viota, don: 21 (padre de Gatan)

Pelegrin de Ribas: 16 (propietario)

Pero Capalbo, don: 20 (espondalero)

Pero Ferrero: 9, 10, 14 (vicario de Ejea y procurador de los clérigos racioneros de Ejea)

Pero Lopeç de Luna, don: 20 (testigo y vecino de Ejea)

Pero Lopez de Sentia: 21 (clérigo racionero de Ejea)

Pero Lopeç de Uchando, don: 6 (sacerdote e hijo de Garcias Sancii de Sancti Stefani, finado), 7, 11, 12 (sacristán), 15, 21 (sacristán) (clérigo racionero de Ejea)

Pero Lopeç d'Undues: 21 (clérigo racionero de Ejea)

Pero Pereç, don: 9 (clérigo no racionero de Ejea)

Pero Ribaforada: 13 (testigo y vecino de Ejea)

Pero Romeu de Viota: 9 (cavero y árbitro)

Pero Sagriello: 16 (propietario)

Pero Sanchez de Ripalla: 16 (testigo)

Pero Sobrino: 5 (Petri Sobrini), 9, 10, 18 (testigo y clérigo no racionero de Ejea) 
Pero Soç, don: 21 (clérigo racionero de Ejea)

Petro Beltran: 2 (propietario)

Petro de Morlans, dompnus: 4 (testigo)

Petro de Ornat, dompnus: 4

Petro de Trillis: 11 (prior de Ejea)

Petro Saniez: 2 (testigo y clérigo racionero de Ejea)

Petrus Garceç d'Oncastiello, don: 10 (fiador)

Petrus Sancii de Peruxa: 2 (testigo), 3 (testigo), 11 (scutiferus)

Petrus Senebucy, dominus: 11 (testigo y milites)

Petrus Suario, dominus: 11 (milites)

Philippus d'Espanniol, dompnus: 5 (fiador)

Remigiro Sentia, don: 12 (fiador y vecino de Ejea)

Rodrigo de Aldaz, fray: 13 (guardián de los Frailes Menores de Ejea, testigo)

Rodrigo Vespen: 9 (clérigo no racionero de Ejea)

San de Baylo: 20 (propietario)

San d'Isuerre, don: 10 (fiador)

Sancha Hecitas, donna: 20 (propietaria)

Sancha Valera, donna: 21 (propietaria)

Sanchio d'Ardiles, don: 9, 10, 14 (clérigo no racionero de Ejea y procurador de los clérigos no racioneros de Ejea)

Sancho Lopeç de Vrez: 20 (propietario y vecino de Ejea, marido de Maria Lopeç y padre de Franqueta)

Sancho Moriello: 21 (propietario)

Sancho Pereç: 21 (adobador, padre de Lop Capellan)

Sancius de Fayet, domnus: 3

Sancius de Laros, dompnus: 7 (testigo)

Sancius de Ventoy: 3 (propietario)

Sancius Egidii: 4, 11 (notario público de Ejea)

Sancius Ortolano: 3 (propietario)

Sanio Feliçana: 2 (hermano de Dominico Feliçana)

Sanya de Ribas, dona: 19 (mujer de Sanyo Blasco)

Sanyo, don: 13 (testigo y vecino de Ejea)

Sanyo Blasco: 19 (corredor y marido de Sanya de Ribas)

Sanyo d'Asso, don: 13 (propietario, finado)

Sanyo de Ribas: 11 (Sancius de Rippis), 19 (finado) (clérigo racionero de Ejea) 
Sanyo Garceç de Burgui: 11 (Sanchus Garçes de Burgui), 12 (clérigo racionero de Ejea)

Sanyo Lopeç de Sentia, don: 19 (propietario)

Teresa de Obanos: 20 (propietaria)

Valero, don: 2 (capellán y hermano de Martinus de Gorreia)

Valero, don: 10 (Justicia de Ejea y fiador)

Personas y autoridades externas:

Bertrando de Cavaniach: 14 (testigo y clérigo)

Egidio Luppi: 14 (milites y testigo)

Egidius de Olith, frater: 11 (testigo y guardián de Zaragoza)

Fortunium de Bergua: 17

Garcia Xemeneç: 13 (procurador de los clérigos racioneros de Biota)

Garsias de Valle: 14 (clérigo y testigo)

Garsias Petri, domino: 8 (arcediano de Eguiart)

Gil de Lopinnen, maystre: 9, 10 (arcediano de Teruel y oficial de Zaragoza)

Ispanus: 14 (notario del Arzobispo de Zaragoza)

Johan d'Onanovença, don: 18 (clérigo de Biota)

Johan Lopeç, don: 9 (abad de Anzano)

Johan Luppi de Eslava: 14 (milites y testigo)

Johan Pereç de Falçes: 8 (Johannes Petri de Falçes), 9, 10 (arcediano de Val de Aibar y juez delegado de la Corte de Tarragona)

Lopus Martini Laviano, domino: 8 (prior de Belath)

Martino Eguidii de Falabus, domino: 8 (canónigo de Pamplona)

Michaeli de Monte Acuto, frater: 11 (testigo y guardián de la orden de los Frailes Menores de Valencia)

Pero, don: 9, 10, 11 (Petrum), 14 (Petro) (obispo de Zaragoza)

Pero Pereç d'Ayerbe: 9 (canónigo de Zaragoza y árbitro)

Petro Alfonsi: 14 (clérigo y testigo)

Petro Sancii de Huart: 8 (clérigo de Pamplona, notario de la diócesis de Pamplona y jurado de la apelación)

Rodericus Guillermi, domino: 8 (canónigo de Pamplona)

Vitalis de Cabanato: 11 (procurador de las diócesis de Pamplona, Zaragoza y del monasterio de Selva Mayor) 
Nombres incompletos:

Berengariis [****]: 14 (clérigo y testigo)

don [roto] Exement: 10 (clérigo no racionero de Ejea)

Egidius [roto]: 5

[roto] Exement: 10

Johan [*******]: 18

[roto] de Garçia Sanz: 2 (testigo y clérigo racionero de Ejea)

[roto] diales: 2 (testigo y clérigo racionero de Ejea)

[roto] Gorreia: 2 (capellán y vicario de Ejea)

Anexo II. Relación de cargos en el capítulo de la iglesia de Ejea (12411299)

\section{Priores}

1273: Exemeno Lupi de Luna

1277: Petro de Trillis

Presbíteros

1287: Garcias Egidii

Vicarios

1241: [...] Gorreia

1274: Pero Ferrero

1283: Pero Ferrero

1279: Albaro

1287: Johannes Artus

1299: Albaro

Capellanes

1241: Michael de Salvador Valero

1297: Exemen Lopez de Mallada

1299: Martin Suari

ca. 1300: Miguel Lopez

Sacristanes

1243: Exemeno de Exeia

1279: Pero Lopeç de Uchando

1299: Pero Lopeç de Uchando

Diáconos

1241: Johannes d'Espanniol 
Clérigos racioneros (en orden de prelación)

1241: 1. Johan de Sant Iuan

2. ${ }^{\circ}[\ldots]$ de Garçia Sanz

3. ${ }^{\circ}$ Beltran Gaio

4. ${ }^{\circ}$ Estevan de Faiet

5. Johan de Darocha

$6 .^{\circ}$ Egidio de Biasos

7. ${ }^{\circ}[\ldots]$ diales

8. ${ }^{\circ}$ Guillem de Iacha

9. ${ }^{\circ}$ Exemeno de Avero

10. Johan de Logran

11. ${ }^{\circ}$ Aznar Lopez

12. ${ }^{\circ}$ Petro Saniez

1256: Johannes d'Espanniol

1274: Martin Suari

Beltran de Hoç

1277: 1. Johannes d'Espanniol

2. ${ }^{\circ}$ Johannes de Darocha

3. Johannes de Arguedas

4. ${ }^{\circ}$ Pero Lopeç de Uchando

5. Açnar Alinç

6. Sanyo de Ribas

7. ${ }^{\circ}$ Fortunius de Alvero

8. Johannes Eximeni

9. ${ }^{\circ}$ Guillermus de Morlans

10. ${ }^{\circ}$ Garçia Petri don Peronet

11. ${ }^{\circ}$ Bartholomeu del Farno

12. ${ }^{\circ}$ Beltran de Hoç

13. ${ }^{\circ}$ Sanyo Garceç de Burgui

14. ${ }^{\circ}$ Eximenus Petri del Bayo

15. Garçia Pereç d'Y Ysuerre

$16 .^{\circ}$ Gonzalbus Luppi de Gradibus

17..$^{\circ}$ Eximeno Petri Abbul

1279: Johannes de Darocha

Pero Lopeç de Uchando

Ferran d'Albaro

Garcia de Morlans 
Beltran de Hoç

Sanyo Garceç de Burgui

1284: Pero Lopeç de Uchando

Xemen Pereç don Abril

Garçia Pereç de Sanguessa

1286: Beltran de Hoç (procurador de los clérigos racioneros)

1295: Sanyo de Ribas (finado)

1299: 1. ${ }^{\circ}$ Bartholomeu

2. ${ }^{\circ}$ Pero Soç

3. ${ }^{\circ}$ Garçia Pereç d'Ysuerre

4..$^{\circ}$ Beltran de Hoç

5. ${ }^{\circ}$ Bartholomeu del Farno

6. Johan Pereç de Santacruz

7. ${ }^{\circ}$ Adam Caçinero

8. ${ }^{\circ}$ Pero Lopeç d'Undues

9. ${ }^{\circ}$ Guillem de Iacha

10. ${ }^{\circ}$ Miguel Lopez de Baylo

11. ${ }^{\circ}$ Garcia Lopez de Barcach

12..$^{\circ}$ Martin Marques

13. ${ }^{\circ}$ Johan de Viota

14. ${ }^{\circ}$ Pero Lopez de Sentia

$15^{\circ}$ Exemen Lopez de Mallada

16. ${ }^{\circ}$ Açnar Alinç

Clérigos no racioneros

1274: 1. Sanchio d'Ardiles

2. ${ }^{\circ}$ Pero Pereç

3..$^{\circ}$ Blascho Balles

4. Johan Lopeç d'Espanyol

5. ${ }^{\circ}$ Pero Sobrino

$6{ }^{\circ}$ Rodrigo Vespen

1283: Sanchio d'Ardiles (procurador de los clérigos no racioneros)

Anexo III. Relación de escribanos y notarios de Ejea (1241-1299).

1241: Guillermus de Exea (escribano)

1243: Guillermus de Iacca (escribano)

1254: Sancius Egidii (notario público de Ejea. Sustituye al escribano Johannes Petri Sobrini). 
1256: Johannis Marquesii (notario público de Ejea)

1263: Johannis Marquesii

1274: Johannis Marquesii

Egidii Garcez (notario público de Ejea)

1277: Dominici Feliçana (notario público de Ejea)

1279: Eniego Martineç (escribano público de Ejea)

1284: Michaelis Marquesii (notario de Ejea)

1286: Bartholomeo Gil (escribano de Ejea)

1287: Michaelis Marquesii

1295: Eniego Martineç

1297: Dominici Feliçana

1299: Dominici Feliçana

ca. 1300: Johan Garcez d'Ortinyones (notario público de Ejea)

\section{Referencias bibliográficas}

ALVAR LÓPEZ, Manuel (1965-1966), «Onomástica, repoblación, historia. (Los “Establimentz" de Jaca del siglo XIII)», Archivo de Filología Aragonesa, 16-17: 101-124.

ALVAR LÓPEZ, Manuel (1987), «La formación del apellido en los antiguos documentos aragoneses.» En Estudios sobre el dialecto aragonés, vol. 1. Zaragoza, Institución Fernando el Católico: 117-121.

Asín GARCíA, Nuria (2000), «El monasterio cisterciense de la Concepción de la Virgen de Cambrón: pasado, presente y futuro», Suessetania, 20: 98-109.

Auría LABAYen, José Ramón (1982), Documentación medieval del Archivo Parroquial de Ejea de los Caballeros: transcripción. Departamento de Historia Medieval de la Facultad de Filosofía y Letras de la Universidad de Zaragoza. Tesis de licenciatura dirigida por Agustín Ubieto Arteta (septiembre de 1982). Ejemplar mecanografiado, Centro de Estudios de las Cinco Villas.

Cabanes Pecourt, María de los Desamparados (2009), Documentos de Jaime I relacionados con Aragón. Zaragoza, Institución Fernando el Católico (Fuentes Históricas Aragonesas, 50).

CANellas LóPEZ, Ángel (ed.) (1993), Colección diplomática de Sancho Ramírez. Zaragoza, Real Sociedad Económica de Amigos del País, CAI-100.

CIERBIDE MARTINENA, Ricardo (2017), «La onomástica histórica de Navarra», Huarte de San Juan. Filología y Didáctica de la Lengua, 17: 6-34.

Cortés Valenciano, Marcelino (2010), Toponimia de las Cinco Villas de Aragón. Zaragoza, Centro de Estudios de las Cinco Villas.

Cortés VAlenciano, Marcelino (2013), «Toponimia de la Carta de población de Ejea de los Caballeros (julio de 1110)», Aragón en la Edad Media, 24: 141-167. 
CoRTÉs VAlenciano, Marcelino (2015-2016), «Los documentos del siglo XIII del Archivo Parroquial de Ejea de los Caballeros. Estudio lingüístico», Archivo de Filología Aragonesa, 71-72: 13-71.

CORTÉS VALENCIANO, Marcelino (2019), «Bienaventurado sea tu nombre: el nombre de las mujeres de Ejea de los Caballeros en la Edad Media (1286-1499)», Ágora (revista de la Asociación Cultural “Ágora Cinco Villas”), 17: 88-93.

Dolç, Miguel (1960), «Antroponimia latina.» En Enciclopedia Lingüística Hispánica. Tomo I. Antecedentes, onomástica, dirigida por M. Alvar et alii, introducción de Ramón Menéndez Pidal. Madrid, Consejo Superior de Investigaciones Científicas: $389-419$.

FALCÓn PÉREZ, María Isabel (2003), Prosopografía de los infanzones de Aragón (1200-1410). Zaragoza, Universidad, Departamento de Historia Medieval, Ciencias y Técnicas Historiográficas y Estudios Árabes e Islámico.

FALCÓN PÉREZ, María Isabel (2007), «Las Cinco Villas, tierra de infanzones.» En Esteban Sarasa Sánchez (coord.), Las Cinco Villas aragonesas, en la Europa de los siglos XII y XIII: de la frontera natural a las fronteras políticas y socioeconómicas (foralidad y municipalidad). Zaragoza, Institución Fernando el Católico (Actas. Historia): 295-322.

FALCón PÉREZ, María Isabel (2008), Los infanzones de Aragón en la Edad Media. Zaragoza, Institución Fernando el Católico.

FERRER y RACAJ, José Felipe (1790), Idea de Exea. Compendio histórico. Pamplona, Imprenta de Benito Cosculluela. (Edición facsímil. Ejea de los Caballeros, Centro de Estudios de las Cinco Villas, 1999).

FORT CAÑEllas, María Rosa (1984), «Sobre onomástica aragonesa medieval», Archivo de Filología Aragonesa, 34-35: 553-579.

FORT CAÑELLAS, María Rosa (1992), «Antroponimia primitiva aragonesa.» En Actas del II Congreso Internacional de Historia de la Lengua Española, vol. II. Madrid, Pabellón de España: 969-980.

FRAGO GRACIA, Juan Antonio (1976), «Notas de antroponimia navarro-aragonesa», Cuadernos de investigación filológica, II: 73-84.

Frago Gracia, Juan Antonio (1977), «Nombres de oficio y situación social en la antroponimia medieval navarro-aragonesa.» En Homenaje a José María Lacarra y de Miguel, Zaragoza, Anubar: 203-222.

GARCÍA DE CORTÁZAR, José Ángel (1991), «Antroponimia en Navarra y Rioja en los siglos X a XII.» En Miguel Ángel Ladero Quesada et alii (coords.), Estudios de Historia Medieval en homenaje a Luis Suárez Fernández. Valladolid, Universidad de Valladolid: 175-191.

GARCÍA DE CORTÁZAR, José Ángel (1995), «Antroponimia en Navarra y Rioja en los siglos X a XII.» En Pascual Martínez (coord.), Antroponimia y sociedad. Sistemas de identificación hispano-cristianos en los siglos IX a XIII. Valladolid, Universidad de Valladolid / Universidad de Santiago de Compostela: 283-296. 
GIL ORRIOS, Asunción, y José Ramón AURÍA LABAYEN (2007), «Fuentes documentales y bibliográficas para el estudio de las Cinco Villas en los siglos XII y XIII.» En Esteban Sarasa Sánchez (coord.), Las Cinco Villas aragonesas, en la Europa de los siglos XII y XIII: de la frontera natural a las fronteras políticas y socioeconómicas (foralidad y municipalidad). Zaragoza, Institución Fernando el Católico (Actas. Historia): 323-436.

GUINOT RODRÍGUEZ, Enrique (2010), «La antroponimia como indicador de la repoblación en el sur de la Corona de Aragón (siglo XIII).» En Monique Bourin y Pascual Martínez Sopena (eds.), Anthroponymie et migrations dans la chrétienté médiévale. Madrid, Casa de Velázquez: 195-211.

LALIENA CORBERA, Carlos (1995), «Los sistemas antroponímicos en Aragón durante los siglos XI y XII.» En Pascual Martínez (coord.), Antroponimia y sociedad. Sistemas de identificación hispano-cristianos en los siglos IX a XIII. Valladolid, Universidad de Valladolid / Universidad de Santiago de Compostela: 297-326.

LALIENA CORBERA, Carlos (2007), «Tierra, poblamiento y renta señorial: una revisión de problemas generales sobre la organización social del espacio en el valle del Ebro del siglo XII.» En Esteban Sarasa Sánchez (coord.), Las Cinco Villas aragonesas, en la Europa de los siglos XII y XIII: de la frontera natural a las fronteras políticas y socioeconómicas (foralidad y municipalidad). Zaragoza, Institución Fernando el Católico (Actas. Historia): 129-150.

LEDESMA RUBIO, María Luisa (1987), «La colonización de las Cinco Villas y su organización social en los siglos XI y XII.» En La Edad Media en las Cinco Villas. Actas de las II Jornadas de Estudios sobre las Cinco Villas (Sos del Rey Católico, 1986). Ejea de los Caballeros, Centro de Estudios de las Cinco Villas: 47-62.

LOMAX, Derek William (1986), «Las dependencias hispánicas de Santa María de la Selva Mayor», Príncipe de Viana. Anejo, 2-3: 491-506.

MARTínEZ SOPENA, Pascual (1994), «Notas sobre la antroponimia hispánica medieval», Medievalismo, 4: 189-197.

MARTíneZ SopenA, Pascual (coord.) (1995), Antroponimia y sociedad. Sistemas de identificación hispano-cristianos en los siglos IX a XIII. Valladolid, Universidad de Valladolid / Universidad de Santiago de Compostela.

MARTíneZ SOPENA, Pascual (1998), «Reflexiones sobre dos listas de hombres buenos: Lugo (1295) y Palencia (1300)», Scripta: estudios en homenaje a Elida García García, vol. I. Oviedo, Universidad de Oviedo: 397-416.

Monterde Albiac, Cristina (2006), «Santa María de Ejea de los Caballeros y su acta de consagración», Aragón en la Edad Media, 19: 391-396.

PAVÓN BENITO, Julia (2007), «Reorganización y cobertura eclesiástica en las Cinco Villas aragonesas (siglo XII).» En Esteban Sarasa Sánchez (coord.), Las Cinco Villas aragonesas, en la Europa de los siglos XII y XIII: de la frontera natural a las fronteras políticas y socioeconómicas (foralidad y municipalidad). Zaragoza, Institución Fernando el Católico: 183-206. 
PÉREZ GuZMÁn, Isidro, y José Miguel JiMÉNEZ ACÍN (1983), «Los monasterios cistercienses de Puylampa y Cambrón, en Sádaba», Suessetania, 4: 24-33.

PIEDRAFITA PÉREZ, Elena (2000), Las Cinco Villas en la Edad Media (siglos XI-XIII). Sistemas de repoblación y ocupación del espacio. Zaragoza, Institución Fernando el Católico.

PIEDRAFITA PÉREZ, Elena (2007), «Sectores sociales y ocupación territorial de las Cinco Villas (siglos XI al XIII).» En Esteban Sarasa Sánchez (coord.), Las Cinco Villas aragonesas, en la Europa de los siglos XII y XIII: de la frontera natural a las fronteras políticas y socioeconómicas (foralidad y municipalidad). Zaragoza, Institución Fernando el Católico (Actas. Historia): 249-294.

PIEL, Joseph (1960), «Antroponimia germánica.» En Enciclopedia Lingüística Hispánica. Tomo I. Antecedentes, onomástica, dirigida por M. Alvar et alii, introducción de Ramón Menéndez Pidal. Madrid, Consejo Superior de Investigaciones Científicas: 421-444.

PIEL, Joseph, y Dieter KREMER (1976), Hispano-gotisches Namenbuch: der Niederschlag des Westgotischen in den alten und heutigen Personen und Ortsnamen der Iberischen Halbinsel. Heidelberg, C. Winter Universitatsverlag.

RAMOS REMEDIOS, Emiliana (2014), «Francos y vascos en el norte de Castilla (IX-XIII): los cambios en las denominaciones personales», Nouvelle revue d'onomastique, 56: $197-225$. 
